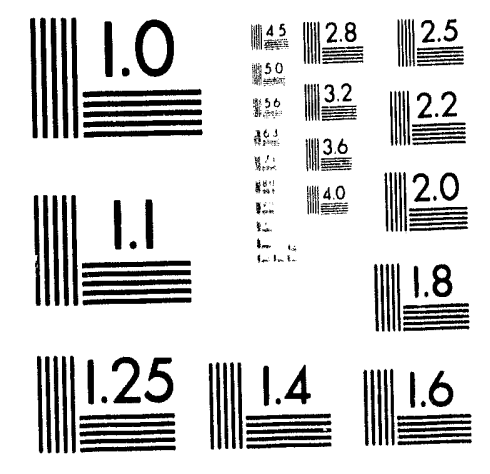



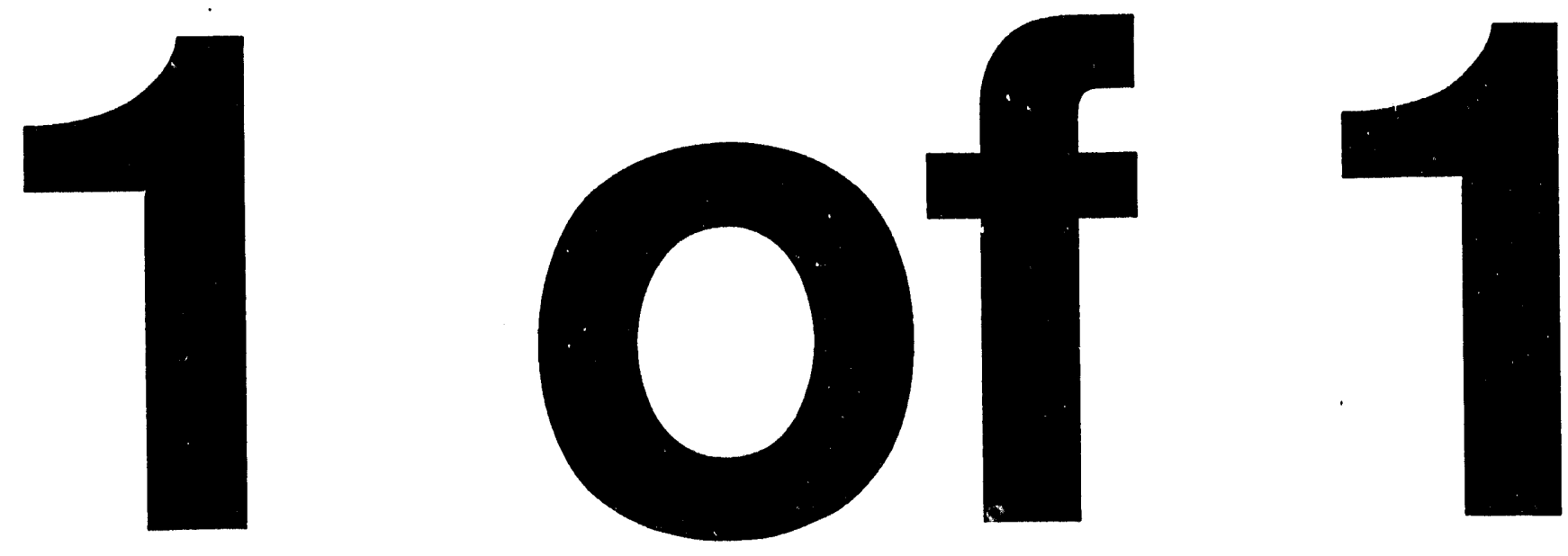
\{09/15/93 08:32 AM\} -.. file: $c: \backslash w f u d d o c s \backslash 93 p l a s m a \backslash e n v i n d a p . d o c$

\title{
Environmental and Industrial Applications of Pulsed Power Systems
}

\author{
E. L. Neau \\ Sandia National Laboratories \\ P.O. Box 5800 \\ Albuquerque, NM 87185
}

All paners must include the following statement:

This work performed at Sandia National Laboratories is supported by the U.S. Depnrtment of Energy under contract DE-ACO4.76DPO0789.

\begin{abstract}
The technology base formed by the development of high peak power simulators, laser drivers, free electron lasers (FEL's), and Inertial Confinement Fusion (ICF) drivers from the early 60 's through the late 80 's is being extended to high average power short-pulse machines with the capabilities of performing new roles in environmental cleanup applications and in supporting new types of industrial manufacturing processes. Some of these processes will require very high average beam power levels of hundreds of kilowatts to perhaps megawatts. In this paper we briefly discuss new technology capabilities and then concentrate on specific application areas that may benefit from the high specific energies and high average powers attainable with short-pulse machines.
\end{abstract}

\section{Introduction to Technology Developments}

Many applications of electron beam, ion beam, or X-ray processing have been described in the literature ${ }^{(1,2,3,4)}$. Low power beam applications, such as crosslinking of polymers in tubular form or on packaging surfaces and sterilization of foods or medical devices, are applications that have been in development for 10 to 20 years using existing accelerator capabilities. These low power accelerators, with over one thousand units installed worldwide, use transformers or capacitively coupled rectifier decks to generate beam potentials of $100 \mathrm{keV}$ to 5 $\mathrm{MeV}$ with average beam powers of up to approximately $200 \mathrm{~kW}(5)$. $\mathrm{RF}$ linear induction accelerators are available for commercial applications and operate at beam energies of up to $10 \mathrm{MeV}$ and average power levels of $50 \mathrm{~kW}$ with possible extension to $250 \mathrm{~kW}^{(6)}$. This paper will give a brief overview of a new class of high average power accelerators and then focus on possible near term applications that are not in the commercial stage. These applications require, and benefit from, short ( $50 \mathrm{~ns}$ to $500 \mathrm{~ns}$ ) electron, ion, or gamma ray pulses with energies between $500 \mathrm{keV}$ and $10 \mathrm{MeV}$ at average beam power levels greater than $200 \mathrm{~kW}$.

The electron and ion beams from large, single-shot, pulsed power machines developed over the last 30 years for the Inertial Confinement Fusion program, for flash X-ray sources for radiation effects studies, or for directed energy weapons

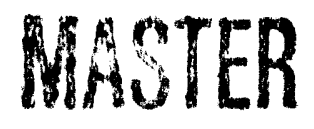

DHETAREUTION OF THIS COOUMENT IS UNLIMITED
RECENI.

OCT O 51993 
programs offer unusual combinations of energy density, temperature, and pressure not attainable in more conventional thermal processes. Unlike thermal processes that heat a total volume, high power beams offer the possibility of efficiently depositing energy in a specific work volume or in a well defined surface layer. Accelerator developments, such as the use of large-scale saturable magnetic switches $(7,8,9)$, high peak power linear induction voltage adders (LIVA's $^{(10,11)}$, and large-area electron and ion beam diodes $(12,13,14)$, with the addition of thermal heat management techniques and an understanding of reliability issues, make this type of accelerator a good candidate for use in high average power industrial processing applications. The machines being developed in the Repetitive High Energy Pulsed Power (RHEPP) project typifies this new generation of high average power accelerator ${ }^{(15)}$.

Selection of energy efficient accelerator technologies, with potential for long life reliable operation, however, requires exterided prototype demonstrations before they can be expected to achieve acceptance in the commercial marketplace where slin. profit margins dictate the amount of risk that can be taken on a new process technology.

\section{Recent High Average Power Accelerator Developments}

The pulsed power technology base developed for defense applications of beams has evolved to a common format of the pulse compression and voltage addition stages for the short-pulse high average power accelerators now in development as shown in Figure 1. The short pulse technology allows the use of LIVA cavities, with METGLAS ${ }^{\circledR}$ magnetic isolation cores, to achieve output voltages from 1 $\mathrm{MeV}$ to as much as $20 \mathrm{MeV}$ at high average currents. The adder cavities may be used to accelerate a central electron beam supplied by an injector, as in the ETA accelerator ${ }^{(9)}$, or they may have a vacuum or magnetically insulated metal stalk on axis, first demonstrated in the $\operatorname{HELIA}^{(10)}$ accelerator, with a single stage electron or ion beam diode on the output of the adder(11).

\section{Figure 1}

Short-pulse accelerators at Physics International, Science Research Laboratories and Sandia National Laboratories, are now beginning to deliver beams with average powers of from $10 \mathrm{~kW}$ to $120 \mathrm{~kW}$ with $350 \mathrm{~kW}$ continuous expected within the next year. The Physics International Compact Linear Induction Accelerator (CLIA), shown in Figure 2 uses thyratrons in the primary pulse compression stage and has ten stages of linear induction voltage addition on a magnetically insulated stalk to achieve a $50 \mathrm{~ns}$ output pulse with a beam accelerating potential of $750 \mathrm{kV}$ at average power levels of $120 \mathrm{~kW}$ for periods of five seconds (16). The Science Research Laboratories SNOMAD IV accelerator, shown in Figure 3, uses semiconductor switches in the primary pulse compression module which can be configured as a beam injector, with dispenser 
cathode, or as a series of LIA beam acceleration stages with a $1 \mathrm{~mm}$ to $6 \mathrm{~mm}$ diameter, $500 \mathrm{~A}$, electron beam ${ }^{(17)}$. The semiconductor switches offer the possibility of multi-kilohertz operation with high average beam power. This device, with a 50 ns FWHM output pulse, is presently delivering a $1.5 \mathrm{MeV}$ electron beam at an average beam power of $38 \mathrm{~kW}$. The Sandia RHEPP accelerator uses an all magnetically switched approach to generate a $1 \mathrm{MeV}$ beam from an oil insulated LIVA, shown in Figure 4, and has been tested at $7-\mathrm{kW}^{(15)}$. This accelerator is being upgraded for continuous $120 \mathrm{~kW}$ operation at $120 \mathrm{~Hz}$ using a Westinghouse alternator as the prime power source. A second accelerator is being assembled for operation in early 1994 which will provide a $2.3 \mathrm{MeV}$ beam, from a vacuum insulated LIVA, with $350 \mathrm{~kW}$ of beam power. A future development will include the substitution of high average power SCR semiconductor switches for the first stages of magnetic pulse compression. The 1 $\mathrm{MeV}$ and $2.3 \mathrm{MeV}$ accelerators are designed to provide large area electron beams at current densities of about $25 \mathrm{~A} / \mathrm{cm}^{2}$ over an area of approximately $1000 \mathrm{~cm}^{2}$ from cold, field emission type cathodes. The $1 \mathrm{MeV}$ RHEPP accelerator is also being used to deliver ion beams for exploration of new, large area, surface modification applications. This new family of short-pulse accelerators minimize power consumption by operating at efficiencies, from wall plug to electron beam, of at least $50 \%$. These high average power accelerators will be important for future industrial applications because they offer the possibility of supplying very high average power beams which are beyond the capabilities of present commercial accelerators.

\section{Figure 2, Figure 3, and Figure 4}

Applications for the new high average power accelerators must be identified which cannot be adequately addressed by less efficient, pure thermal, techniques for putting energy into the desired product volume, because of the relatively high capital costs and need for radiation shielding. Also, changing regulatory requirements may sliminate some traditional chemical treatments, such as the use of ethylene oxide or methyl bromide, which may, in turn, make accelerator treatment methods more appealing. To gain acceptance, the technology must be shown to offer a robust and cost effective solution to a specific need.

\section{Introduction to Environmental Applications}

In reviewing possible uses of short-pulse high average power accelerators, one has to be impressed by the fact that many of our current environmental problems have been identified since the early 70's or even earlier. Many experiments have been conducted using irradiation sources to destroy the toxic compounds now being identified as hazardous by-products of our industrial society. Many experiments have been conducted identifying the capabilities of radiation sources in killing bacteria that are harmful to society, such as e-coli and salmonella. 
What appears to be needed is the establishment of an infrastructure to provide the ready availability of cost effective, long-life, high average power machines for incorporation into industrial plants, for materials fabrication, chemical production, food pasteurization, medical product sterilization, or as a treatment method for waste effluents that pollute air or ground waters.

\section{An Organic Waste Destruction Application}

Electron beams have been shown to be very effective, $>99 \%$, in destroying a number of organic compounds such as trichloroethylene, propanes, benzenes, phenols, and halogenated hydrocarbons in contaminated water by Cooper and Nickelsen at Florida International University with Waite and Kurucz at the University of Miami ${ }^{(18)}$, and Matthews at the Lawrence Livermore National Laboratory ${ }^{(19)}$. Others have shown effective destruction of pesticides and solvents such as Malathion, Lindane, carbon disulfide and carbon tetrachloride by electron beam irradiation ${ }^{(20)}$. The irradiation of aqueous solutions creates the free radicals, $\mathrm{e}_{\mathrm{aq}}, \mathrm{H}^{*}$, and $\mathrm{OH}^{*}$ as the injected electrons lose energy in the process creating a shower of ever lower energy electrons ${ }^{(21)}$. These free radicals react with organic molecules producing salts, $\mathrm{CO}_{2}$, and water in a process called mineralization. Hydrogen peroxide is the stable oxidant formed during irradiation and it can also impact the conversion process. Electron beam irradiation has also been shown to be capable of destroying ferrocyanides in solution ${ }^{(22)}$.

A possible new application of high average power electron beams arose out of an attempt to identify an organic waste destruction problem which appeared to be expensive and potentially dangerous when using traditional thermal incineration or other processes. The Hanford nuclear reservation, in southwestern Washington State, has approximately 60 million gallons of waste that is a mixture of organic compounds and low-level and high-level radioactive wastes stored in 177 single and double-walled underground tanks ${ }^{(23)}$. Because the waste consists of mixtures of caustic salts, organic compounds, and radioactive materials, the waste cannot be separated into high level and low-level waste streams without extensive chemical treatment. In addition to the organic compounds, such as ethylene diaminetetraacetic acid (EDTA) used in the PUREX process to recover uranium and plutonium, some of the tanks contain ferrocyanide salts in a sodium nitrate/sodium nitrite matrix. Twenty three of the tanks periodically release quantities of flammable gases such as hydrogen and nitrous oxide in explosive concentrations. The stored waste has been altered from its original composition by continual radiolysis due to the decay processes of the radioactive components, chemical reactions between the various constituents, and thermal effects. It is estimated that perhaps as much as 100 Mrads have been accumulated since the storage of materials began in 1943. High average power accelerators have the capability of delivering doses much higher than 100 Mrads in a relatively short time to speed up the mineralization process. 
Competing processes such as supercritical water oxidation, wet air oxidation, steam reforming, or treatment with hydrogen peroxide, ozone, or ultraviolet light are also being evaluated. These concepts have the potential drawbacks that they involve either liquid dissolution, which increases the volume by factors of 3 to 5 , or the process operates at very high temperatures, which may affect subsequent separation of high and low level radioactive waste components.

A series of electron beam organic destruction experiments, by Patterson et al.(24), were conducted on a tank 101 -SY simulant prepared using a formula provided by Herting of the Westinghouse Hanford Company (2.5) in the geometry shown in Figure 5. Two $1 \mathrm{MeV}$ accelerators provided total doses to simulant samples of up to $1600 \mathrm{Mrad}$ with dose rates of $2.5 \times 10^{8} \mathrm{rad} / \mathrm{s}$ from the KITE accelerator and $2.7 \times 10^{14} \mathrm{rad} / \mathrm{s}$ from a PI-112 accelerator. As shown in Figure 6, the higher dose rate accelerator, with a pulse width of $30 \mathrm{~ns}$, proved to be more than three times as effective in organic destruction capability. Approximately 1500 Mrad will be required for $95 \%$ organic destruction, from a short-pulse accelerator, based on these experimental results.

\section{Figure 6}

The data obtained in this experiment, being somewhat limited in scope, will require more accurate assessment before proposing the use of the electron beam organic destruction technique at the Hanford site. Based on these preliminary experiments, the technique has been proposed as a method of mitigating the Hanford wastes. The temperature rise of the waste material, in the proposed process, would be limited to keep the maximum temperature below the boiling point of the material, in turn limiting the irradiation to about $19 \mathrm{Mrad}$ per pass. The limited temperature rise would therefore require waste material cooling and multiple passes through the irradiator. Preliminary costs for treating the Hanford waste with a high average power electron beam accelerator, using RHEPP technology, have been roughly estimated to be approximately $\$ 11 /$ gallon including capital, operating, and maintenance costs for an electron beam plant with a treatment rate of 20 gallons per minute. Material handling costs are not included in this estimate.

\section{Proposed Approaches to Flue Gas Cleanup Applications}

Fossil fuels are used in many power plants worldwide producing sulfur dioxide $\left(\mathrm{SO}_{2}\right)$ and nitrogen oxides $\left(\mathrm{NO}_{\mathrm{X}}\right)$ as gaseous emissions in the fuel burning process. These emissions are known to be active in producing acidic rainfall that damages trees, lakes, and buildings. Utilities which rely on high sulfur coal, in the U.S., will be most affected by new regulations, such as the New Clean Air Act, that will require significant $\mathrm{NO}_{\mathrm{X}}$ emissions reduction after 1995. Non thermal plasma techniques offer an energy efficient approach to the 
simultaneous destruction of both types of gaseous oxides. Non-thermal plasma processes can be induced by electron beam irradiation or by treatment in a high electric field geometry which accelerates the electrons present in the gas stream. Both methods increase the electron temperature while leaving the bulk of the gas at near ambient temperature. The dissociation and ionization of the gas stream produces free radicals which subsequently cause decomposition of the pollutants.

Electron beam treatment of flue gases has been the subject of research in Japan, the USA, Germany, and Russia since $1970(26,27,28,29)$. Electron beam irradiation of flue gases has shown simultaneous removal of more than $94 \%$ of $\mathrm{SO}_{2}$ and $80 \%$ of the $\mathrm{NO}_{\mathrm{X}}$ in tests in Japan ${ }^{(30)}$. This multi-step process is outlined in Figure 7.

\section{Figure 7}

The byproducts of this process are ammonium sulfate and nitrate that can be used as fertilizer. A pilot plant, also using this approach, has been constructed at the Electropower Station Kaweczyn, in Poland, that has a gas flow capacity of $20000 \mathrm{Nm}^{3} / \mathrm{h}$ as a by-pass loop on a main flue gas stream of $250,000 \mathrm{Nm}^{3} / \mathrm{h}^{(31)}$. The flue gas contains $0.9-1.2 \mathrm{~g}$ of $\mathrm{SO}_{2} / \mathrm{Nm}^{3}$ and $0.2-0.55 \mathrm{~g}$ of $\mathrm{NO}_{\mathrm{X}} / \mathrm{Nm}^{3}$. Two ELW-3 a.ccelerators, from the Institute of Nuclear Physics in Novosibirsk, Russia, each supply $50 \mathrm{~kW}$ at $700 \mathrm{keV}$ to provide the required electron beam power. Additional pilot plants are in operation in Japan at the Ebara facility in Fujisawa ${ }^{(32)}$ and at the Chuba Electric Plant in Nagoya ${ }^{(33)}$. The beam power required, for typical flue gas irradiation of about $1 \mathrm{Mrad}$, is estimated to be about $1.5 \%$ to $3 \%$ of the total plant generating capacity ${ }^{(34)}$. It is this requirement that is driving the development of very high average power accelerators to satisfy cost and sizing considerations. The electron beam treatment process is also being investigated to treat the exhaust emissions from the metropolitan vehicle tunnel under the Tokyo Bay ${ }^{(35)}$.

Another approach to reducing $\mathrm{SO}_{2}$ and $\mathrm{NO}_{\mathrm{X}}$ emissions in flue gases, which bypasses the concerns of shielding of high voltage electron beam sources, consists of using pulsed corona discharges in the flowing gas stream to create free radicals similar to those produced by the electron beam approach. The pulsed corona can be produced by applying an $\mathrm{AC}$ voltage to electrodes, separated by a dielectric barrier, as a silent discharge process in the gas or by applying a short highvoltage pulse to the electrodes in a high field configuration as shown in Figures $8 \mathrm{a}$ and $8 \mathrm{~b}$. The silent discharge was first used by Siemens in the 1850's for the production of ozone and is still in use today in water purification plants. The Italian National Electricity board (ENEL) has supported pulsed corona experiments at a power plant near Venice in cooperation with the University of Padua $(36,37)$. Work on pulsed corona destruction of $\mathrm{SO}_{2}$ and $\mathrm{NO}_{\mathrm{X}}$ has also been performed at the Florida State University(38). 


\section{Figures $8 a$ and $8 b$}

Both pulsed corona reactor (PCR) methods produce free radicals at the tip of prebreakdown streamers in the gas. The discharge is arrested in the silent discharge, or dielectric barrier, configuration by the reduction in applied field as charge builds up on the dielectric medium and in the coaxial high field geometry by tailoring the applied pulse length to terminate before the formation of an arc discharge. Efficient destruction of the $\mathrm{SO}_{2}$ and $\mathrm{NO}_{\mathrm{X}}$ or other organic contaminants, such as volatile organic contaminants (VOC's), in the flowing gas stream rely on short pulse operation to avoid transferring energy to the gas ions that would raise the bulk temperature of the gas $(39,40)$. Pulse parameters, such as rate of voltage rise and pulse length, determine the energy and charge deposited in the flue gas volume in the form of streamers ${ }^{(41)}$. Pulse amplitudes depend on reactor dimensions but range from $50 \mathrm{kv}$ to $200 \mathrm{kV}$ and pulse lengths range from $50 \mathrm{~ns}$ to a few hundred nanoseconds. A fraction of the field required to sustain the streamer may be supplied by a DC bias circuit to improve the efficiency of the pulsed source in coupling to the streamer formation. The pulsed corona method is less efficient than the electron beam process, requiring about 50 $\mathrm{eV}$ per $\mathrm{NO}_{\mathrm{X}}$ molecule removed (compared to $14 \mathrm{eV}$ per $\mathrm{NO}_{\mathbf{x}}$ molecule removed Ising an e-beam), and the amount of pulsed corona power which must be 4 operly conditioned is on the order of 5 percent of the power plant output ${ }^{(42)}$. The power conditioning required for the pulsed corona method does not involve as many stages of pulse compression nor does it require a high average power electron beam diode and beam window which must be kept free of fly ash and corrosion. The elimination of these components should greatly reduce the power conditioning system capital costs to perhaps as little as $\$ 2 / w$ to $\$ 3 / w^{(43)}$.

\section{Introduction to Industrial Applicatiuns:}

Material surface treatments like galvanizing, sputtering, electroplating, and plasma spraying have made new products possible and opened new markets. Multi-use technology based on pulsed UV sources or short-pulse high average power electron and ion beam processors is beginning to open the development of next-generation cost-effective, environmentally conscious materials surface treatment. These new techniques will require the availability, for the first time, of low-cost reliable sources of pulsed energy for high volume industrial applications.

\section{Paint Stripping Using Pulsed UV Radiation:}

The Environmental Protection Agency, under the Toxic Substance Control Act (TSCA) is reducing the permissible exposure levels (PEL's) for many types of 
solvents. The PEL for methylene chloride, used in paint stripping operations, is scheduled to be reduced from $500 \mathrm{ppm}$ to $25 \mathrm{ppm}$ by the mid-1990's. The emerging technology of composite airframe components is also driving the search for a non-damaging method of paint removal in the aircraft maintenance industry. Improvements in productivity and elimination of a hazardous work environment can all be obtained in the FlashBlast process by using an intense $3 \mathrm{~ms}$ burst of UV light coupled with a blast of $\mathrm{CO}_{2}$ pellets (44). Experiments have demonstrated complete removal of polyurethane types of paint commonly used on airframes at a cost of a few dollars per square foot.

\section{Ceramics Processing:}

Electron beams with a few megavolts of energy can penetrate several millimeters into ceramics and carbon or boron composites. Input beam energy is converted to heat with nearly $100 \%$ efficiency within the target material. Pulsed accelerators, using short-pulse high average power technology, can easily heat materials in less than one microsecond. These beams can be propagated in a one atmosphere environment eliminating the need for vacuum chamber processing. The beam energy-time profile can be tailored to obtain desired heating rates and treatment volumes. The emerging high average power accelerators also are demonstrating overall electrical efficiency of about $50 \%$ which has the promise of supporting low cost operations in high throughput applications.

\section{Ceramic and Composite Joining}

One possible application for high average power beams is in the joining of ceramic or carbon based materials or in the bonding of these materials to a substrate material(45). A joining or brazing material, with a melting temperature much higher than the materials to be joined can conceptually be used to form bonds with this technique. If the joining material has a higher atomic number (higher density) than the ceramic material, the electron beam deposition is greater in the joining material creating a higher temperature at the joint rather than in the bulk of the ceramic. The concept is shown in Figure 9a with a calculated temperature profile given in Figure $9 \mathrm{~b}$.

\section{Figures 9(a) and 9(b)}

\section{Powder Synthesis}

Pulsed electron beams may be used to vaporize materials in a reactive gaseous environment which favors the formation of useful nanophase powders such as silicon nitride. Applying approximately $14.5 \mathrm{~kJ} / \mathrm{g}$ to silicon surface in a nitrogen environment could produce $300 \mathrm{~g} / \mathrm{h} / \mathrm{w}$ of high purity silicon nitride at a cost of approximately $\$ 1 / \mathrm{kg}$ to $\$ 10 / \mathrm{kg}$ using a RHEPP-like $350 \mathrm{~kW}$ high average 
power accelerator. These estimates should be compared to a cost of about $\$ 20 / \mathrm{kg}$ to $\$ 200 / \mathrm{kg}$, depending on grade, for powder production by conventional methods(45).

\section{Introduction to Metal Processing Using Ion Beams}

Researchers in the Russia have demonstrated the improvement in a number of material surface properties by bombardment with pulsed ion beams $(46,47)$. This new technology has the potential to improve hardness, corrosion resistance, and tribological properties of materials for use in hostile environments. Intense, pulsed, high energy Ion BEam Surface Treatment (IBEST) can produce surface conditions ranging from localized high temperature annealing to surface melting, both followed by rapid thermal quenching to ambient temperatures as shown in Figure $10^{(48)}$. In metals this can produce complex surface alloys, by liquid phase mixing, and/or non-equilibrium microstructures including amorphous, disordered crystalline, and nanocrystalline phases. Other potential applications include etching of polymer films, surface glazing and sealing of ceramic surfaces, and cost-effective dry processes for surface deburring, polishing, and cleaning without the use of potentially harmful solvents. The unique energy deposition characteristics of high energy ion beams allows this technology to be developed for the bonding of thin films to substrates. Unlike the laser beams that deposit their energy near the surface $(\approx 30 \mathrm{~nm})$ or are reflected by the surface, ion beams deposit their energy throughout their multi- $\mu \mathrm{m}$ range. Ion beams also have the unique capability to deposit energy preferentially near the end of their penetration depth, in the interior of the sample, due to the inverse dependence of ion stopping power with energy. Ion beams offer the possible advantage of treating large $\left(200-1000 \mathrm{~cm}^{2}\right)$ surface areas for reduction of edge effects and lower cost, high throughput, materials processing applications.

Figure 10, Ion beam energy deposition

\section{Surface Smoothing and Modification}

The rapid heating of the top 1 to 10 microns of a material surface provided by an ion beam, with a current density of a few $\mathrm{A} / \mathrm{cm}^{2}$ and an energy of approximately $1 \mathrm{MeV}$, can easily bring metals and ceramics to the melting temperature. Figures 11, 12, and 13 show a titanium machined surface, a Metglas $(\mathbb{R}$ surface, and an alumina ceramic surface that have been smoothed by 1 $\mathrm{MeV}, 60 \mathrm{~ns}, 10 \mathrm{~J} / \mathrm{cm}^{2}$ mixed carbon and proton ion beam. The Metglas $(\mathbb{k})$ magnetic properties have not been evaluated following the surface melt treatment. Very smooth surfaces may have application in medical prosthesis fabrication and possibly as reduced electron emission surfaces in high voltage applications. 


\section{Figures 11, 12, and 13}

The results of treating a type $\mathrm{O}-1$ tool steel surface, shown in Figure 14, with a $10 \mathrm{~J} / \mathrm{cm}^{2}, 1 \mathrm{MeV}$ mixed proton and carbon beam illustrate some of the effects of the IBEST surface modification. The surface of the 0-1 steel was converted from an equilibrium ferrite and carbide microstructure to a mixture of amorphous material and retained metastable austenite. The equilibrium carbides were absent in the beam-treated layer, indicating that they had been dissolved during melting and then frozen in solution by the rapid cooling.

\section{Figure 14}

\section{Sub-surface Heating}

When ions stop in materials they deposit energy preferentially near the end of their range because of an inverse dependence of stopping power with ion energy ${ }^{(49)}$.This peak in energy deposicion is called the Bragg peak. Different ion species and energies can be used to give a deposition profile tailored to deposit most of the beam energy at the maximum penetration depth. The peaked deposition profile shown in Figure 15, for $0.9 \mathrm{MeV}$ protons in titanium, provides a unique IBEST capability to melt subsurface layers and interfaces without melting the material surface. This may provide a new method of bonding thin films to substrates, perhaps with greatly improved adhesion. Ion beam pulses with proton energies of over $500 \mathrm{keV}$, with pulse lengths of $100 \mathrm{~ns}$ or less, are required to produce significant $(\mathrm{x} 2)$ peak in the deposition profile. The pulse length is limited by the requirement that the deposited heat energy not be significantly conducted away from the treated zone during the heating process. Availability of ion beams with spectral and specie purity are required and may be provided by the Magnetically-confined Anode Plasma ion beam system from Cornell University $(49,50)$.

\section{Figure 15, Bragg peak}

\section{Ion Diode Developments}

Operation of the Magnetically-confined Anode Plasma (MAP) ion beam source was demonstrated with repetitive pulse rates of $100 \mathrm{~Hz}$ in 10 pulse burst mode operation at Cornell $(49,50)$. An improved version of this system is now being fielded on the RHEPP facility ${ }^{(15)}$ for burst mode operation. The MAP source operates on the principle of drawing ions from an anode plasma rather than from a solid anode as used in a single pulse mode application. A fast gas valve on the axis of the anode assembly produces a puff that is delivered to the anode through a supersonic nozzle to produce a highly localized volume of gas directly in front of the surface of a fast driving coil. After preionization by a 1 microsecond induced 
electric field, the fast coil is energized, inducing a loop voltage of up to $20 \mathrm{kV}$ on the gas volume, driving a breakdown to full ionization and pushing the resulting plasma toward the flux-excluding anode field shaping electrodes in about 1.6 microseconds to form a thin, magneticaliy confined plasma layer. The RHEPP pulse then accelerates ions from this plasma layer to form the ion beam. The anode plasma can be formed using a variety of gases including hydrogen, nitrogen, and argon. The beam propagates ballistically to the target plane, also located in the vacuum chamber, as shown in Figure 16.

\section{Figure 16, MAP Ion Beam Diode}

The selection of ions with larger mass, such as nitrogen or argon, will allow energy deposition in surface layers of less than 1 micron. This process can deposit sufficient energy to vaporize the surface for cleaning, etching, or vapor deposition applications.

\section{Materials Processing Using Electron Beams}

Many of the materials treatment processes that can be done with ion beams may be performed with greater penetration depths by using suitable energy electron beams. In experiments at the Lawrence Livermore Laboratory, Elmer deposited energy from a $6 \mathrm{MeV}, 60 \mathrm{~ns}$, electron beam into O-1 tool steel and found an increase, by about a factor of 3 , in the hardness of the material ${ }^{(51)}$. The hardness increased over a depth of about $2 \mathrm{~mm}$ while the range of the electrons in the material was $1 \mathrm{~mm}$.

The short range of the megavolt ion beams require the deposition process be carried out in a vacuum. Electrons could be deposited in materials surrounded by atmospheric pressure gases when differentially purıped windows are be developed.

\section{Food Irradiation}

Consideration of food irradiation is driven primarily by concerns for the safety of the food supply. As many as 10,000 deaths per year, in the US., are attributed to food poisoning, and wide-spread use of food irradiation could drastically reduce this rate ${ }^{(52)}$. Reduction of food spoilage and extension of marketable shelf-life is a second reason for using food irradiation. As much as $40 \%$ of produce harvested in the fields is lost due to spoilage before it reaches the consumer. Up to $90 \%$ of the $f$ sh fish harvest is lost due to spoilage. This loss amounts to several billion dollars annually and could be drastically reduced by the use of foud irradiation. Third-world countries have a more severe food contamination and spoilage problem than does the United States, due to a less advanced transportation and 
refrigeration system ${ }^{(52)}$, so the use of food irradiation could help increase the available food supply.

Dose levels are generally divided into three ranges:

$\begin{array}{ll}\text { Disinfestation } & \leq 100 \mathrm{Krad} \\ \text { Pasteurization } & 100 \text { to } 300 \mathrm{Krad} \\ \text { Sterilization } & >300 \mathrm{Krad} \text { to } 3 \mathrm{Mrad}\end{array}$

The scientific background for the effectiveness of removing bacteria and insect infestation is extensive. Food irradiation treatment data has been comprehensively reviewed ${ }^{(53)}$. There is no doubt that the treatment is extremely effective in removing such contaminants as salmonella, listeria, and E. coli. Salmonella cell populations are reduced by at least 6 orders of magnitude with an exposure of $300 \mathrm{Krad}$ ( $3 \mathrm{Kgrays})$. Annual health care costs in the U.S. due to salmonellosis alone are estimated at approximately $\$ 2 \mathrm{~B}^{(54)}$. There is a large data base to show that no radiolytic byproducts are introduced into the food as a result of the treatment process at the FDA approved treatment levels $(52,55)$. Food irradiation can undoubtedly reduce the loss of life and costs of medical treatment that is now attributed to illness from food ccntamination, in the US. and world society.

Presently there are a limited number of choices for accelerators for food irradiation processing $(56,57)$. These accelerators are based on RF Linac technology or DC accelerator technology. Low power X-ray and electron beam generating machines are available from $\mathrm{MeV}$ Industrie, France, AECL Accelerators, Canada, and the Titan Corp. as well as from several Russian Institutes. These accelerators have limited capability for extension to the high average power levels required for high through-put applications. Typically these accelerators have output power levels of $100 \mathrm{~kW}$ or less. A large scale food operation is desirable to make food treatment profitable. In order to treat a large volume of foods, the X-ray mode will likely be used because of the greater depth of penetration compared to using electrons. The power requirement is estimated to be in the range of $500 \mathrm{~kW}$ to $1000 \mathrm{~kW}$ to make an accelerator facility cost effective. Customer education, additional regulatory actions, and development of long-life systems will be required to expand the use of short-pulse, high average power accelerators into the food irradiation market.

\section{Conclusion}

Over 20 years of scientific research have been conducted on beneficial applications of electron and ion beams. Most industrial applications used beam power levels of up to a few hundred $\mathrm{kW}$ with beam energies of less than $1 \mathrm{MeV}$. Defense applications have concentrated primarily on single pulse accelerator 
operation with beam energies of up to a few 10 's of $\mathrm{MeV}$. Various university experiments have demonstrated the usefulness of beams in mitigating organics and other type of industrial pollution. Irradation of foodstuffs with Colbalt-60 sources is now seeing some acceptance in the US. Scientists and engineers dedicated to fighting the cold war are now finding themselves in a position to convert defense oriented devices, such as short-pulse simulators, to economically sound approaches that deal with environmental and exciting new industrial applications. Availability of long-life, short-pulse, high average power accelerators, pulse compression components, and high power ion and electron beam diodes is occurring on a parallel path with the development of an increasing awareness of society's need for ways of dealing with problems such as waste pollution, bacteriological outbreaks, and an increasing desire for new and less polluting manufacturing methods. These problems can be, at least partially, attributed to increasing population densities and waste management policies of the past. The magnitude of some of the present pollution problems now being identified may seem to greatly overshadow society's ability to pay for the treatment needed to restore the environment. Creative and economical solutions from the scientific establishment, with the assistance of short-pulse, high average power beams, may present a way out of this dilemma. The applications presented in this review are not intended to be all inclusive, but rather to indicate just some of the possibilities for pulsed beams that are available now and waiting for sufficient economic and political emphasis to be commercialized.

\section{References:}

[1] Fletcher, P. M., et al., "An Overview of EB Equipment and Trends for the 90's", in Proceedings of TAPPI Polymers, Laminations and Coatings Conference, Boston, MA, September 4-7, 1990.

[2] Nablo, S. V., "Developments in Transformer Accelerators and the Technology of Pulsed Electron Sterilization at Ultra-High Dose Rates", in Proceedings of the International Conference on Technical Developments and Prospects of Sterilization by Ionizing Radiation, Vienna, Austria, April 1-4, 1974.

[3] Pikaev, A. K., "Radiation Processing in the U.S.S.R.", in Priceedings of the Seventh International Meeting on Radiation Processing, Noorowijkerhout, The Netherlands, April 23-28, 1989, pp. 870-878.

[4] Particle Accelerators and Their Uses, Chapter 11, Scharf, V. editor Harwood Academic Publishers, 1991

[5] Thompson, C., and Cleland, M., "High-Power Dynamitron Accelerators for X-ray Processing," in Nuclear Instruments and Methods in Physics Research, B40/41, pp1137-1141, 1989.

[6] Kerluke, D., and McKeown, J., "The Commercial Launch of IMPELA," in Radiation Physics and Chemistry, Vol 42, pp 511-514, 1993. 
[7] Neau, E. L., et al., "COMET-II, A Two-Stage, Magnetically Switched Pulsed-Power Module", in $\mathrm{C}$ nnference Record of the 1984 Sixteenth Power Modulator Symposium, June 18-20, 1984, pp. 292-294.

[8] Neau, E. L., "COMET: A 6 MV, 400 kJ, Magnetically Switched Pulse Power Module", in Proceedings of the Fourth IEEE Pulsed Power Conference, Albuquerque, NM, June 6-8, 1983, pp. 246-250.

[9] Clark, J., et al., "Design and Initial Operation of the ETA-II Induction Accelerator", in Proceedings of the 1988 Linear Accelerator Conference, October 3-7, 1988.

[10] Ramirez, J. J., et al., "The Four Stage Helia Experiment", in Proceedings of the Fifth IEEE Pulsed Power Conference, Arlington, VA, June 10-12, 1985, pp. 143-146.

[11] Ramirez, J. J., et al., "Performance of the Hermes-III Gamma Ray Simulator", in Proceedings of the Seventh IEEE Pulsed Power Conference, Monterey, CA, June 11-14, 1989, pp. 26-31.

[12] Rosocha, L. A., et al., "An Overview of Progress in Electron Beam Pumping Technology for KrF Lasers", in Proceedings of Second Workshop on KrF Laser Technology, Banff, Alberta, Canada, September 19-22, 1990.

[13] Brucker, J. P., et al., "Foil-Support Structures for Large Area Diodes", to be published in Proceedings of the Ninth IEEE International Pulsed Power Conference, Albuquerque, NM, June 21-23, 1993.

[14] Mesyats, G. A., "Vacuum Discharge Effects in the Diodes of HighCurrent Electron Accelerators", in Proceedings of Fourteenth International Symposium on Discharges and Electrical Insulation in Vacuum," Santa Fe, NM, September 17-20, 1990, pp. 1-7.

[15] Johnson, D. L., et al., "Results of Initial Testing of the Four Stage RHEPP Accelerator", to be published in Proceedings of the Ninth IEEE International Pulsed Power Conference, Albuquerque, NM, June 21-23, 1993.

[16] Ashby, S., et al., "CLIA - A Compact Linear Induction Accelerator System", in Proceedings of the Eighth IEEE International Pulsed Power Conference, San Diego, CA, 1991, pp. 940-942.

[17] Goodman, D. L., et al., "High Energy Linear Induction Accelerators for Material Processing Applications", in Proceedings of the Radiational Technology International Conference, Boston, MA, 1992, Vol. 1, pp. 302-307.

[18] Cooper, W. J., et al., "High-energy Electron Beam Irradiation: An Advanced Oxidation Process for the Treatment of Aqueous Based Organic and Hazardous Wastes", in Proceedings of A Symposium on Advanced Oxidation Processes for the Treatment of Contaminated Water and Air, June 4-5, 1990.

[19] Matthews, S. M., et al., "Decomposition of Halogenated Hydrocarbons Using Intense Bremsstrahlung", in Proceedings of the Eighth International Meeting on Radiation Processing, Beijing, P.R.C., September 13-18, 1992, p. 689.

[20] Cappadona, C., et al., "Possible Use of High-Level Radiation for the Degradation of Some Substances Present in Urban and Industrial Waters", in Proceedings of the International Symposium on the Use of High Level Radiation in Waste Treatment, Status and Prospects, Munich, 1975. 
[21] Singh, A., et al., "The Use of High-Energy Radiation for the Treatment of Wastewater: A Review", Environmental Canada 8th Wastewater Treatment Symposium, Montreal, Canada, 1985, pp269ff.

[22] Touhill, C. J., et al., "The Effects of Radiation on Chicago Metropolitan Sanitary District Municipal and Industrial Wastewaters", in Proceedings of the 41st Annual Conference of the Water Pollution Control Federation, Chicago, IL, September 22-27, 1968.

[23] Babad, H., and Deichman, J. L., Waste Management '91, Tucson, AZ, 1991, p. 847.

[24] Patterson, Brown, and Samlin, Sandia National Laboratories Report SAND92-1969•UC-602.

[25] Herting, D. L., private communication.

[26] Kawamura, K., and Aoki, S., "Study on Application of Ionizing Radiation to Flue Gas Desulfurization", Japan Atomic Energy Society, Vol. 14, p. 597, 1972.

[27] Frank , N. W., and Hirano, S., "The Electron-Beam Flue Gas Treatment Process", in Radiation Physics and Chemistry, Vol. 35, pp. 416-421, 1990.

[28] Jordan, S., "On the State of the Art of Flue Gas Cleaning by Irradiation with Fast Electrons," in Radiation Physics and Chemistry, Vol. 35, pp. 409-415, 1990.

[29] Shvedchikov, A. P., et al., "Radiation-Chemical Removal of $\mathrm{NO}_{\mathrm{X}}$ and $\mathrm{SO}_{2}$ From Exhaust Gases", in Radiation Physics and Chemistry, Vol. 31, pp. 15-19, 1988.

[30] Namba, Tokunaga, et al., "The Study on Electron Beam Flue Gas Treatment for Coal Fired Thermal Plant in Japan", in Radiation Physics and Chemistry, Vol. 42, Numbers 1-3, July-September 1993, p. 669ff.

[31] Chmielewski, et al., "Pilot Plant for Flue Gas Treatment with Electron Beam - Start Up and Two Stage Irradiation Tests", in Radiation Physics and Chemistry, Vol. 42, Numbers 1-3, July-September 1993, p. 663ff.

[32] Maezawa,A., and Izutsu, M., "Application of E-beam Treatment to Flue Gas Cleanup in Japan", to be published in the Proceedings of the NATO Advanced Research Workshop on Non-Thermal Plasma Techniques for Pollution Control, Cambridge University, UK, September 21-25, 1992.

[33] Namba, H., et al., "Basic Study on Electron Beam Flue Gas Treatment for Coal-Fired Thermal Plant," in Proceedings of the International Conference on Evolution in Beam Applications, Takasaki, Japan, November 5-8, 1991, pp 476 481.

[34] Genuario, et al., "Development of the Electron Beam Dry Scrubbing of Flue Gas Utilizing HPTA Technology", in Ninth International Conference on High-Power Particle Beams, Washington, DC, May 25-29, 1992.

[35] Machi, S., "Radiation Technology in the 1990's", , in Radiation Physics and Chemistry, Vol. 42, Numbers 1-3, July-September 1993, p. 13ff.

[36] Dinelli, G. L., et al., 1990, "Industrial Experiments on Pulse Corona Simultaneous Removal of $\mathrm{NO}_{\mathrm{X}}$ and $\mathrm{SO}_{2}$ From Flue Gas", in IEEE Transactions on Industrial Applications, Vol. 25, pp. 535-541. 
[37] Giambertti, I., "Modeling of Plasma Catalytic Rəduction of $\mathrm{NO}_{\mathrm{X}}$ and $\mathrm{SO}_{2}$ in Flue Gases", to be published in the Proceedings of the NATO Advanced Research Workshop on Non-Thermal Plasma Techniques for Pollution Control, Cambridge University, UK, September 21-25, 1992.

[38] Clements, J. S., et al., "Combined Removal of $\mathrm{SO}_{2}, \mathrm{NO}_{\mathrm{X}}$, and Fly Ash From Simulated Flue Gas Using Pulsed Streamer Corona" in IEEE Transactions on Industrial Applications, Vol. 25, pp. 62-69, 1989.

[39] Vogtlin, G., "Pulsed Coronal Discharge for Combined Removal of $\mathrm{SO}_{2}$, $\mathrm{NO}_{\mathrm{X}}$, and Fly Ash from Flue Gas", to be published in the Proceedings of the NATO Advanced Research Workshop on Non-Thermal Plasma Techniques for Pollution Control, Cambridge University, UK, September 21-25, 1992.

[40] Helfritch, D. J., "Pulsed Corona Discharge for Hydrogen Sulfide Decomposition", IEEE/IAS Annual Meeting, 1991.

[41] Rea and Yan, "Energization of Pulse Corona Induced Chemical Processes," to be published in the Proceedings of the NATO Advanced Research Workshop on Non-Thermal Plasma Techniques for Pollution Control, Cambridge University, UK, September 21-25, 1992.

[42] Penetrante, B. M., "Pollution Control Applications of Pulsed Power Technology", to be published in the Proceedings of the 9th International Pulsed Power Conference, Albuquerque, NM, June 21-23,1993

[43] Bhasavanich, D. et al., "Flue Gas Irradiation Using Pulsed Corona and Pulsed Electron Beam Technology", to be published in the Proceedings of the 9th International Pulsed Power Conference, Albuquerque, NM, June 21-23,1993

[43] White, R., Maxwell Laboratories, San Diego, private communication

[44] Struve, K. W., and Turman, B. N., "Potential Ceramics Processing Applications with High-Energy Electron Beams", presented at Twentieth International Conference on Plasma Science, Vancouver, BC, Canada, 1993.

[45] Remnev, G. E., and Shulov, V. A., "Practical Applications of High Power Ion Beams", in Ninth International Conference on High -Power Particle Beams, Washington, DC, May 25-29, 1992.

[46] Kutuzov, V. L., Ovsyannikov, M. Yu, Romanov, I. G., Pogrebnk, A. D., and Remnev, G. E., "Mechanical and Frictional Properties of Tool Steels Exposed to HPIB Irradiation", Mechanical and Frictional Properties of Tool Steels, November 8, 1988, pp. 361-364.

[47] Stinnett, R. W., et al., "The Use of Pulsed Ion Beams for Thermal Surface Treatment", 20th International Conference on Plasma Science, Vancouver, BC, Canada, June 7-9, 1993.

[48] Greenly, J. B., et al., "Magnetically Insulated Ion Diode with a GasBreakdown Plasma Anode," in Journal of Applied Physics, Vol. 63, p. 1872, 1988.

[49] Greenly, J. B., et al., "Plasma Anode Ion Diode Research at Cornell: Repetitive Pulse and 0.1 TW Single-Pulse Experiments", in Proceedings of the Eighth International Conference on High Power Particle Beams, B. N. Breizman and B. A. Knyazev, Eds., Novosibirsk, p. 199, 1990.

[50] Elmer, J., to be published in the Proceedings of the 1993 International Welding Conference, Houston, TX, April 1993. 
[51] International Consultative Group on Food Irradiation, "Facts About Food Irradiation," printed by the International Atomic Energy Agency, Vienna, Austria, December, 1991

[52] Thayer, D., "Irradiation for Control of Food-Borne Pathogens on Meats and Poultry"' The Agricultural Research Institute international Conference on Safeguarding the Food Supply Through Irradiation Processing Techniques, Orlando, FL, October 1992.

[53] Kampelmacher, E., "Impact and Benefit of Radiation Technology in Science," in Radiation Physics and Chemistry, Vol 35, pp 9-11, 1990.

[54] Diehl, J., "Safety of Irradiated Foods," Marcel Dekker, Inc., New York, 1990.

[55] Sadat, T., "Dual Linear Accelerator System for Use in Sterilization of Medical Disposable Supplies," Nuclear Instruments and Methods in Physics Research, B56/57, p1226, 1991.

[56] Ungrin, J., "Development of Accelerators for Radiation Applications," Proceedings of the 12th International Conference on the Applications of Accelerators in Research and Industry, Denton, TX, November, 1992. 


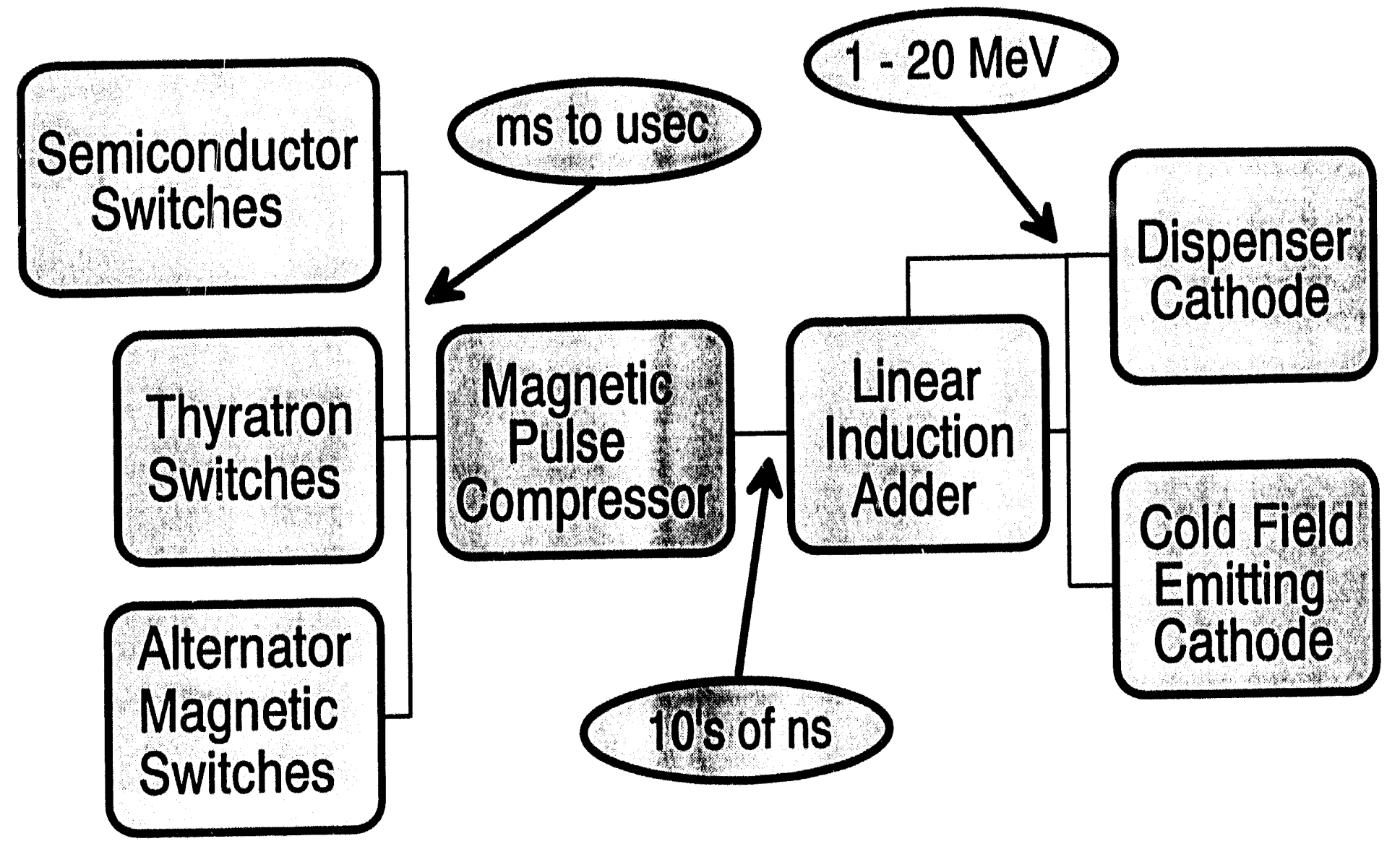

Figure 1 - Short-pulse high average power accelerators use a common approach to pulse compression and beam generation. 


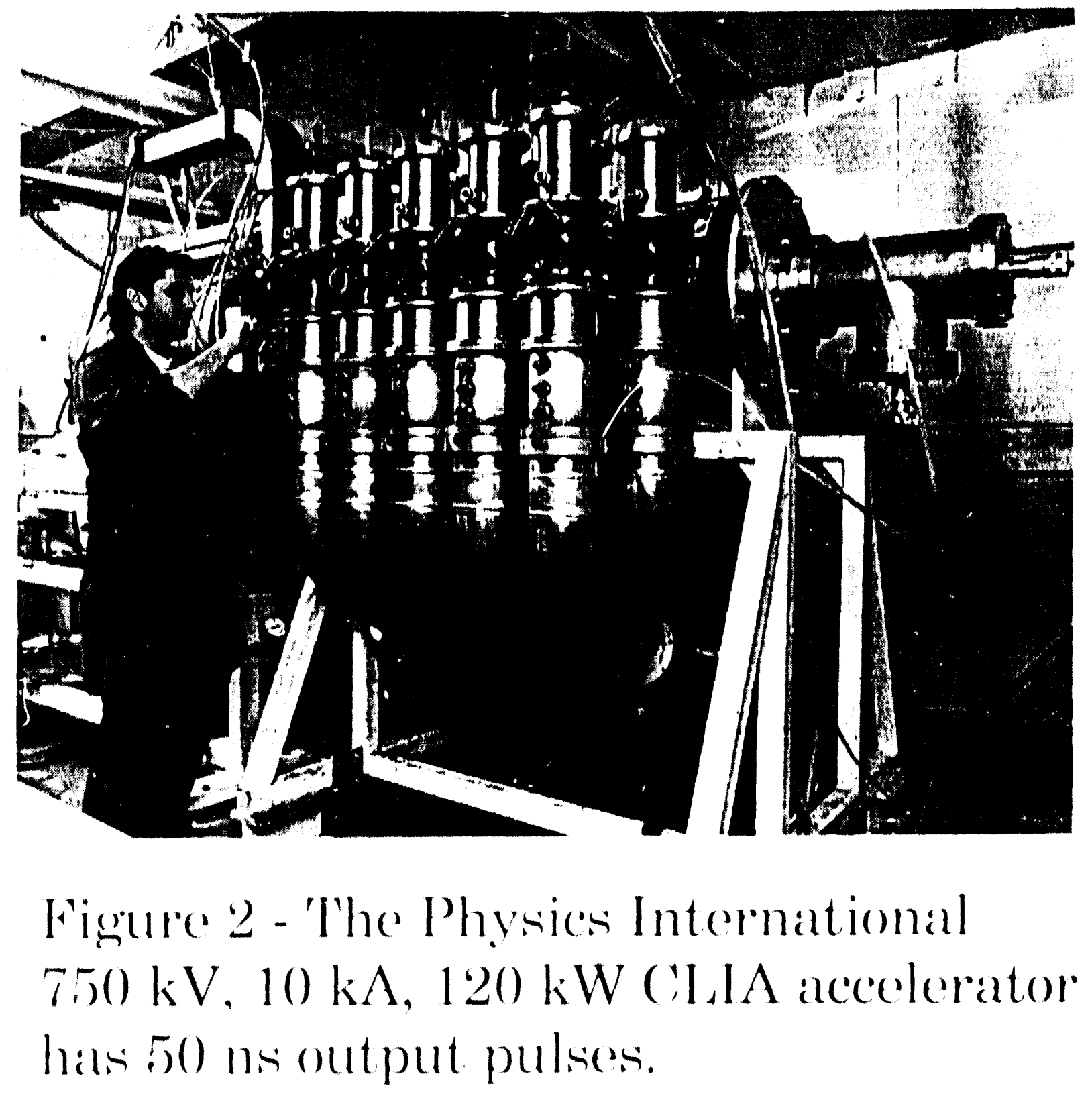




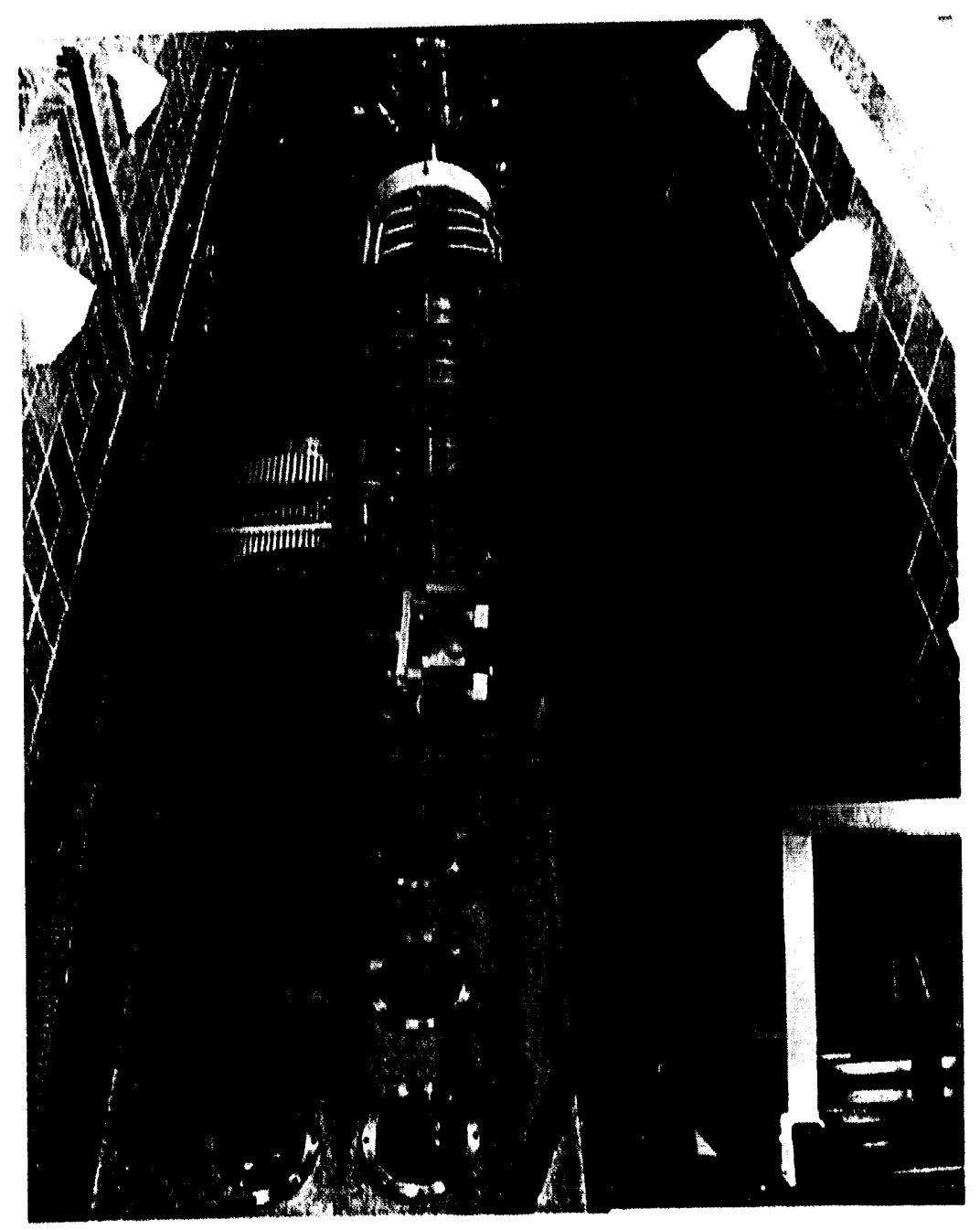

Figure 3 - The Science Research Laboratories SNOMAD IV accelerator delivers $1.5 \mathrm{MeV}$, $500 \mathrm{~A}$, beams with $38 \mathrm{~kW}$ average power. 


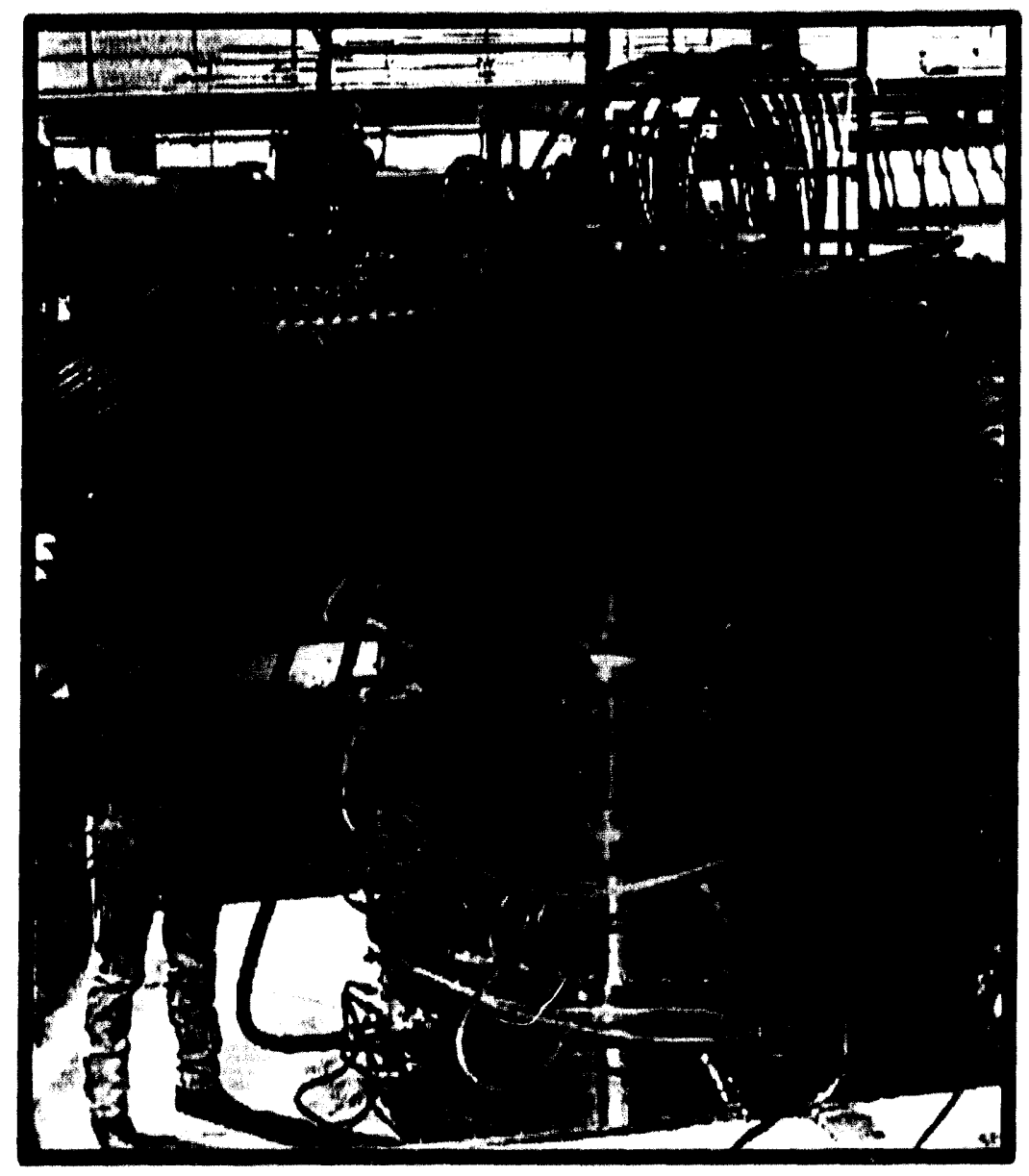

Figure 4 - The RHEPP $1 \mathrm{MeV}$ accelerator uses an oil filled LIVA to deliver $25 \mathrm{kA}$, $60 \mathrm{~ns}$ pulses with $7 \mathrm{~kW}$ of continuous beam power at 5 PPS. This system is being upgraded for $120 \mathrm{~kW}, 120$ PPS operation. 


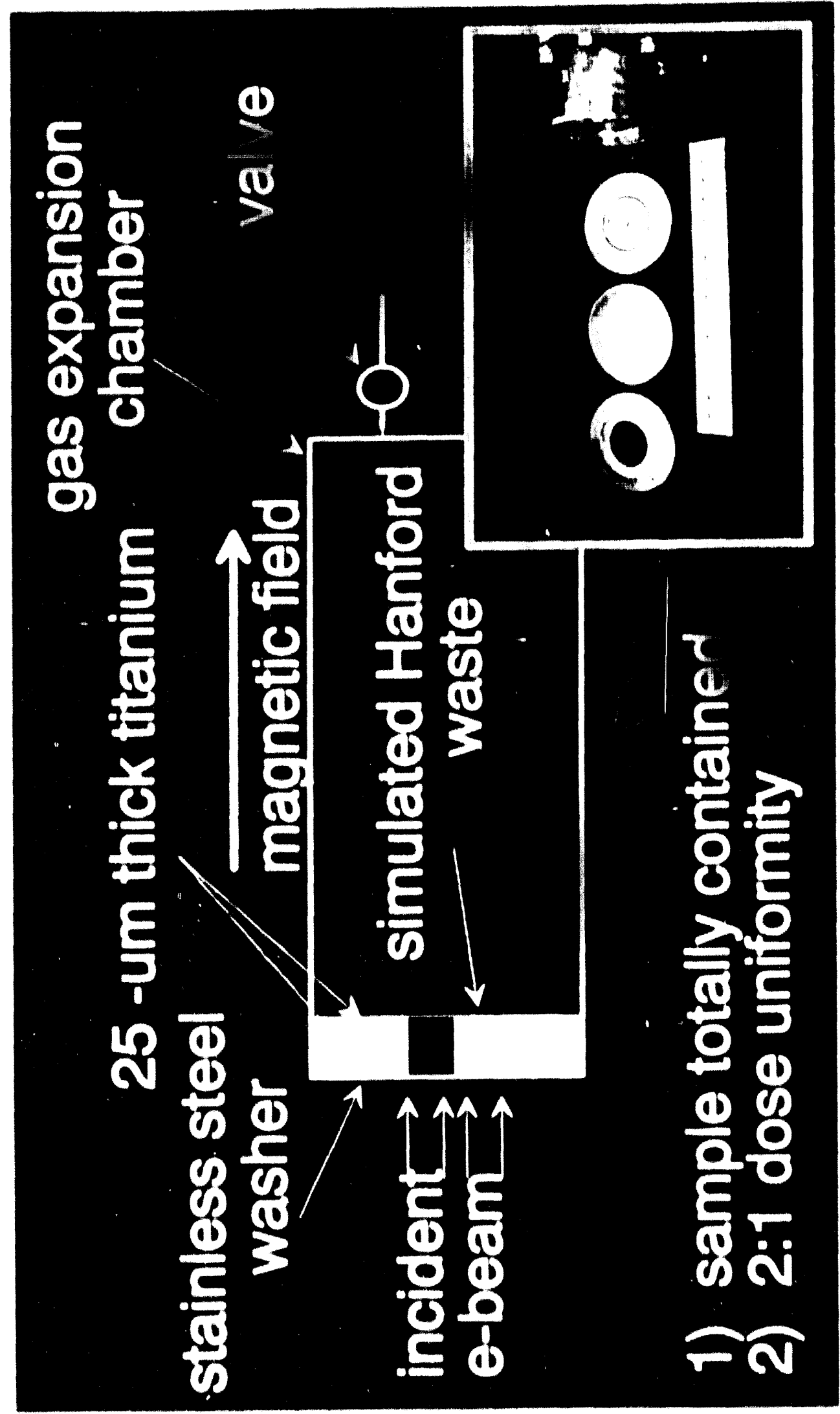




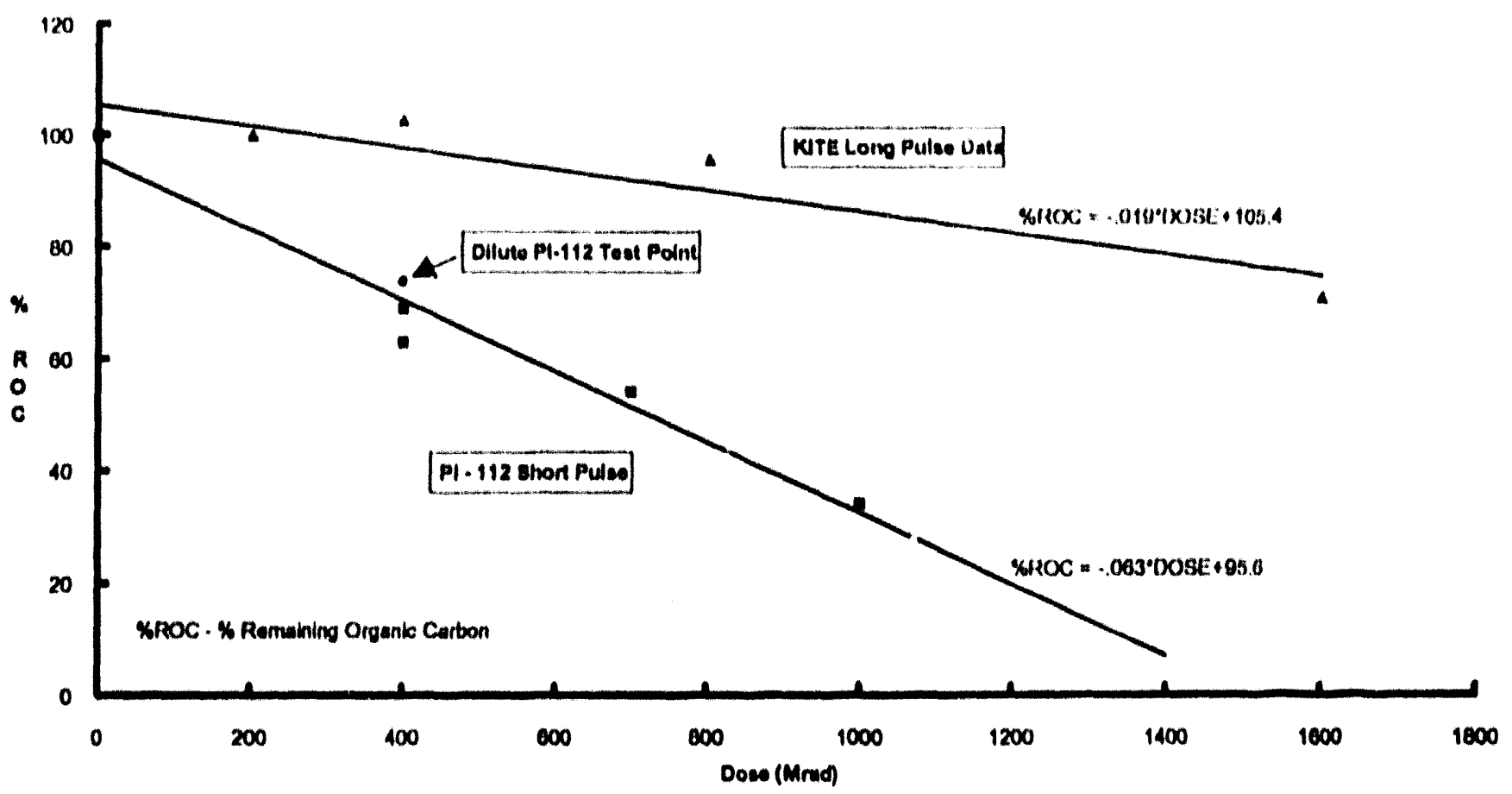

Figure 6 - Results of pulsed irradiation of simulated Hanford waste show complete destruction of organics will require about $1500 \mathrm{Mrad}$ from a short pulse accelerator. 


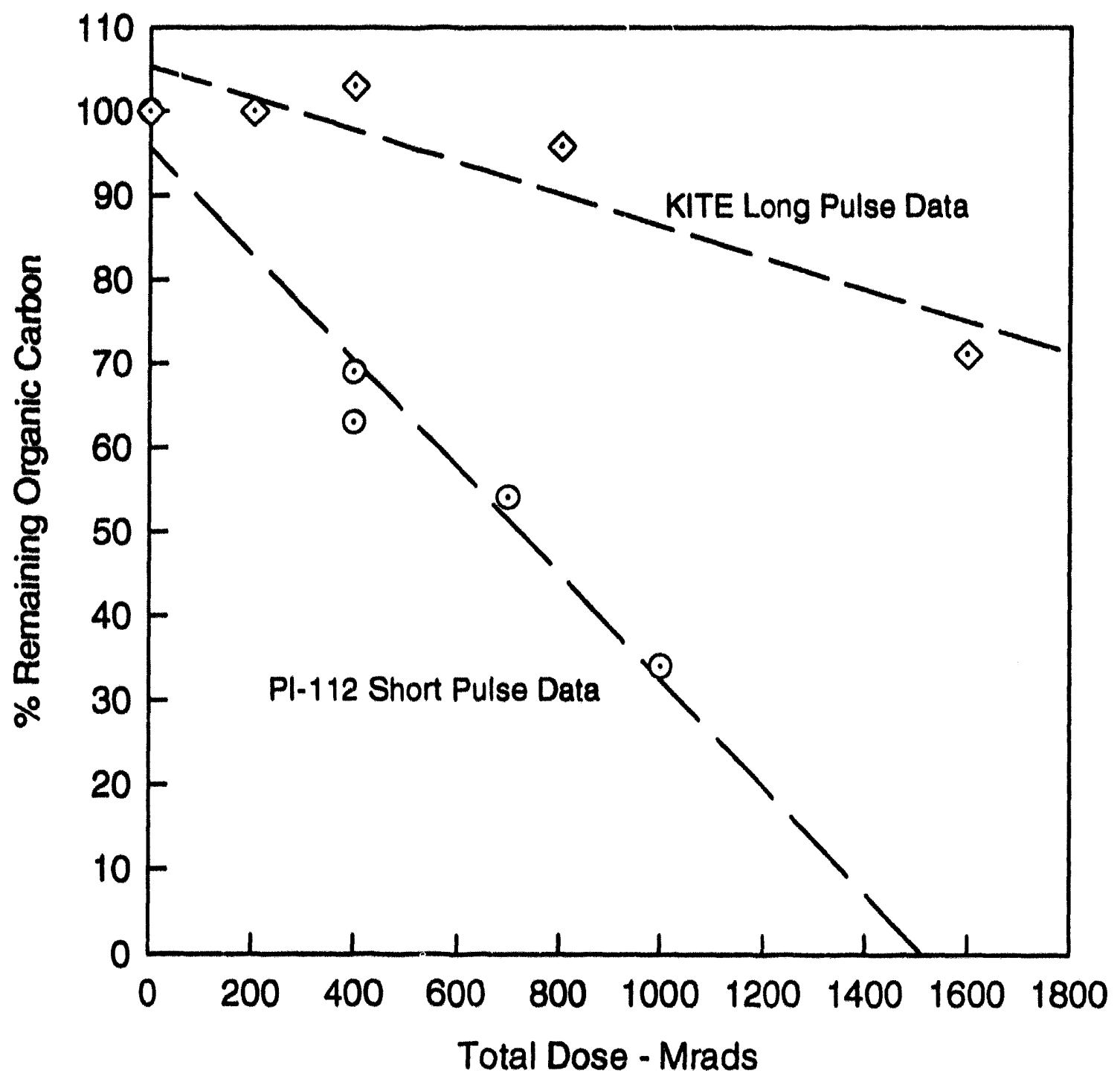




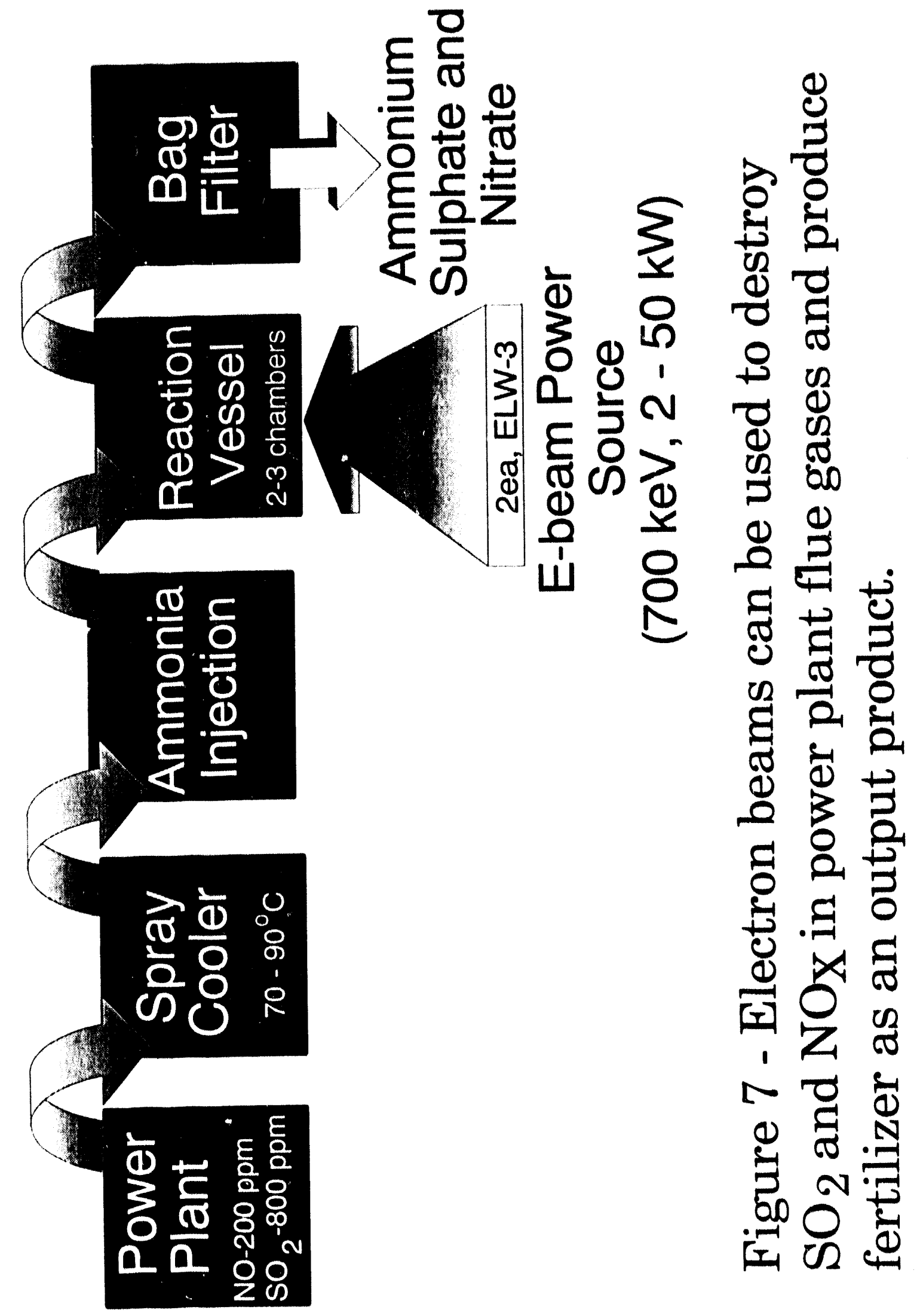




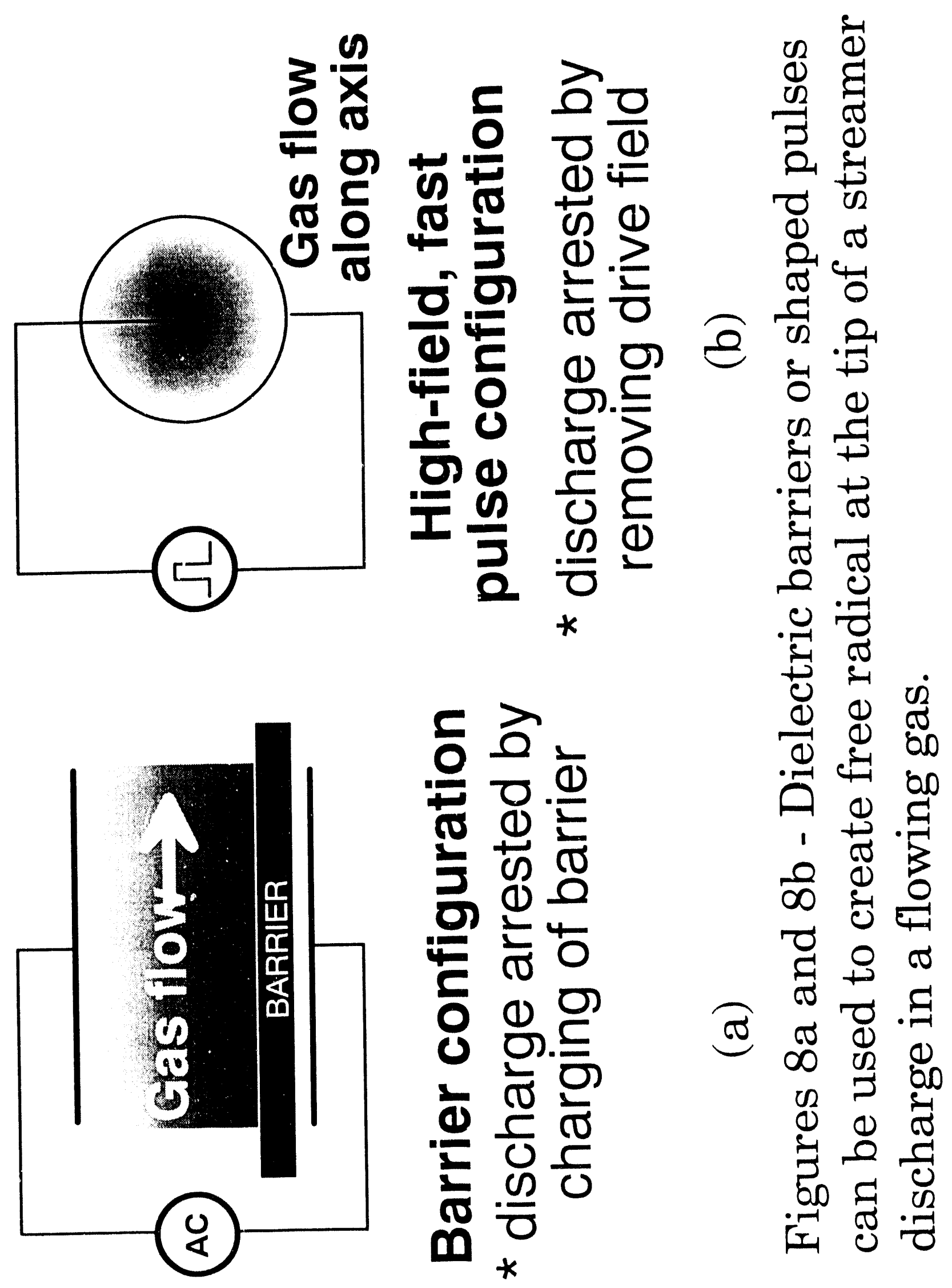



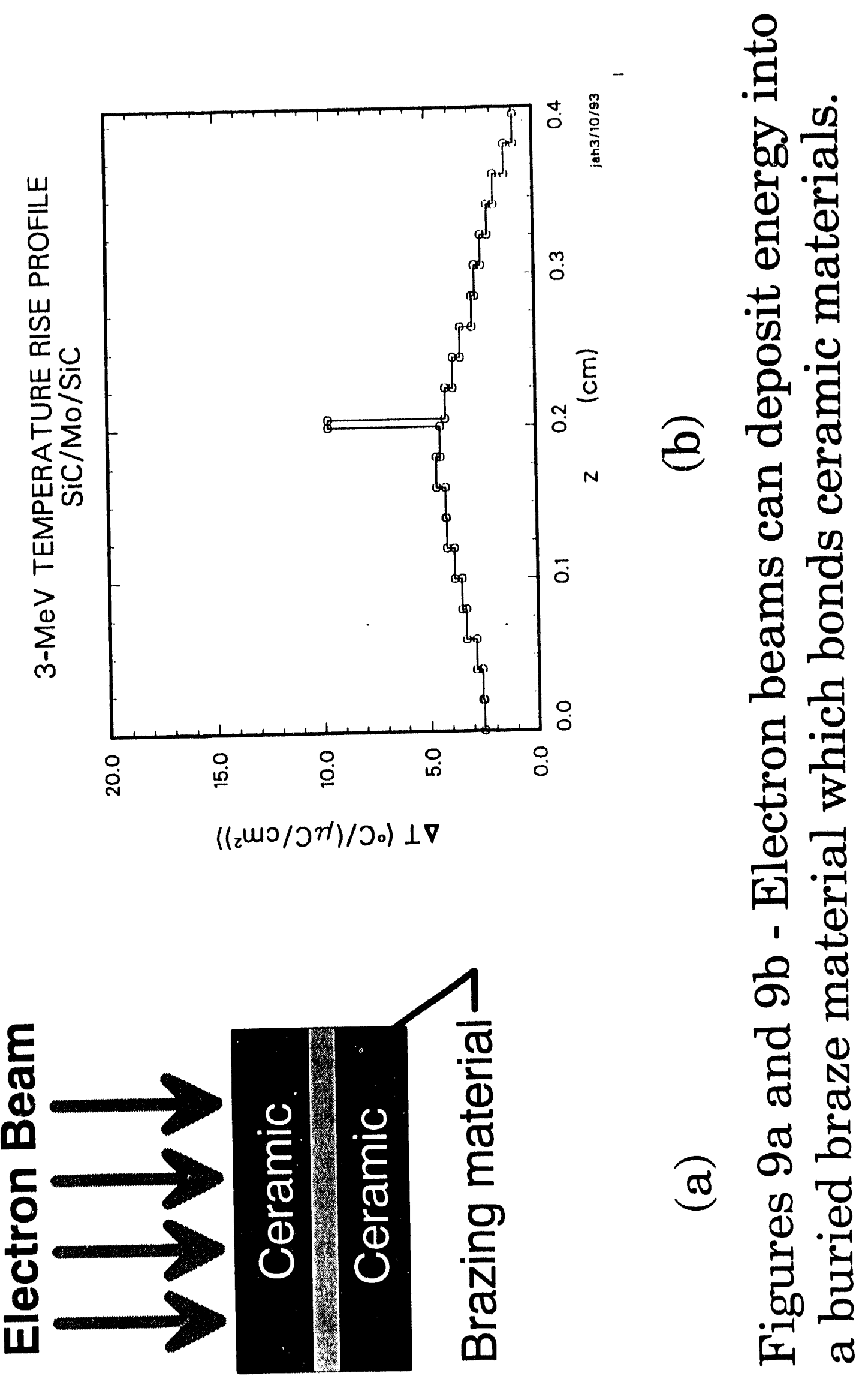


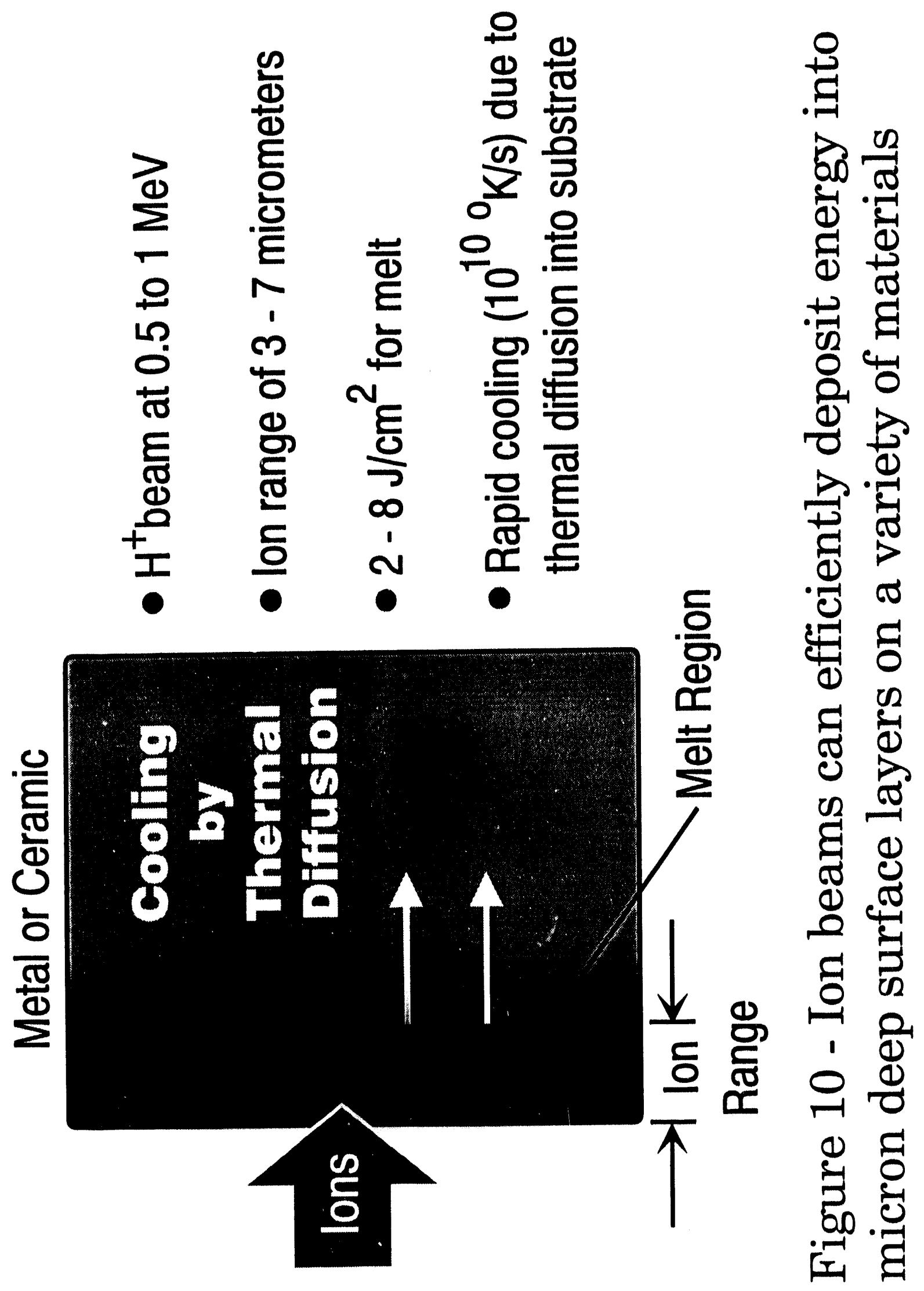




\section{త్ర}

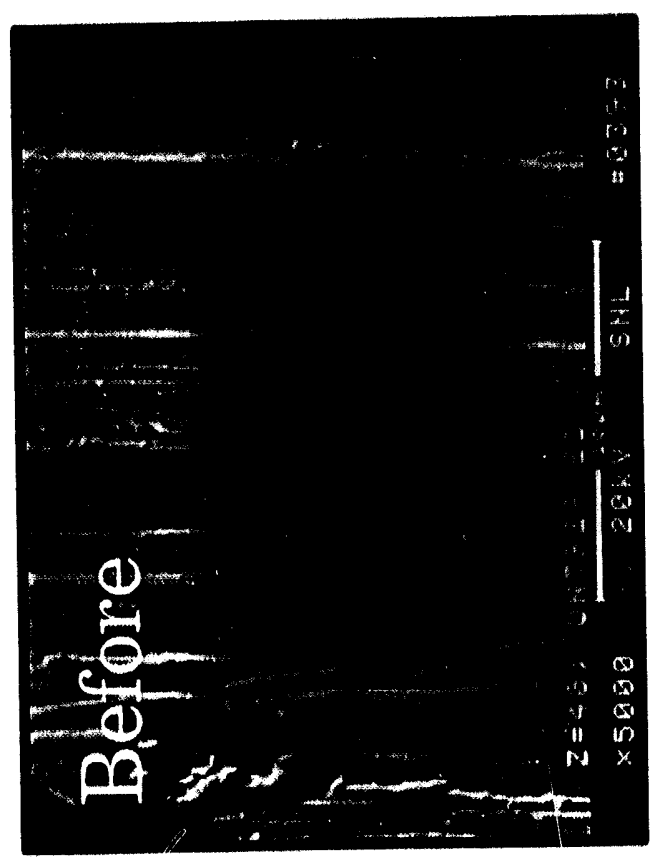

$\widehat{e}$

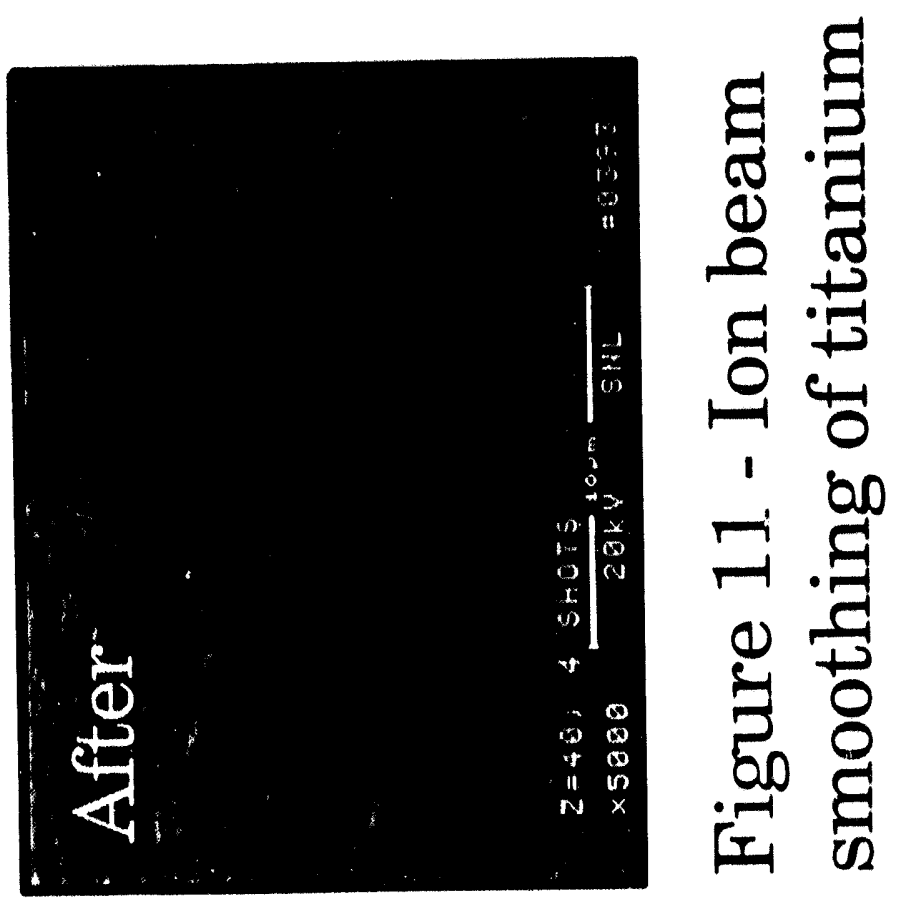




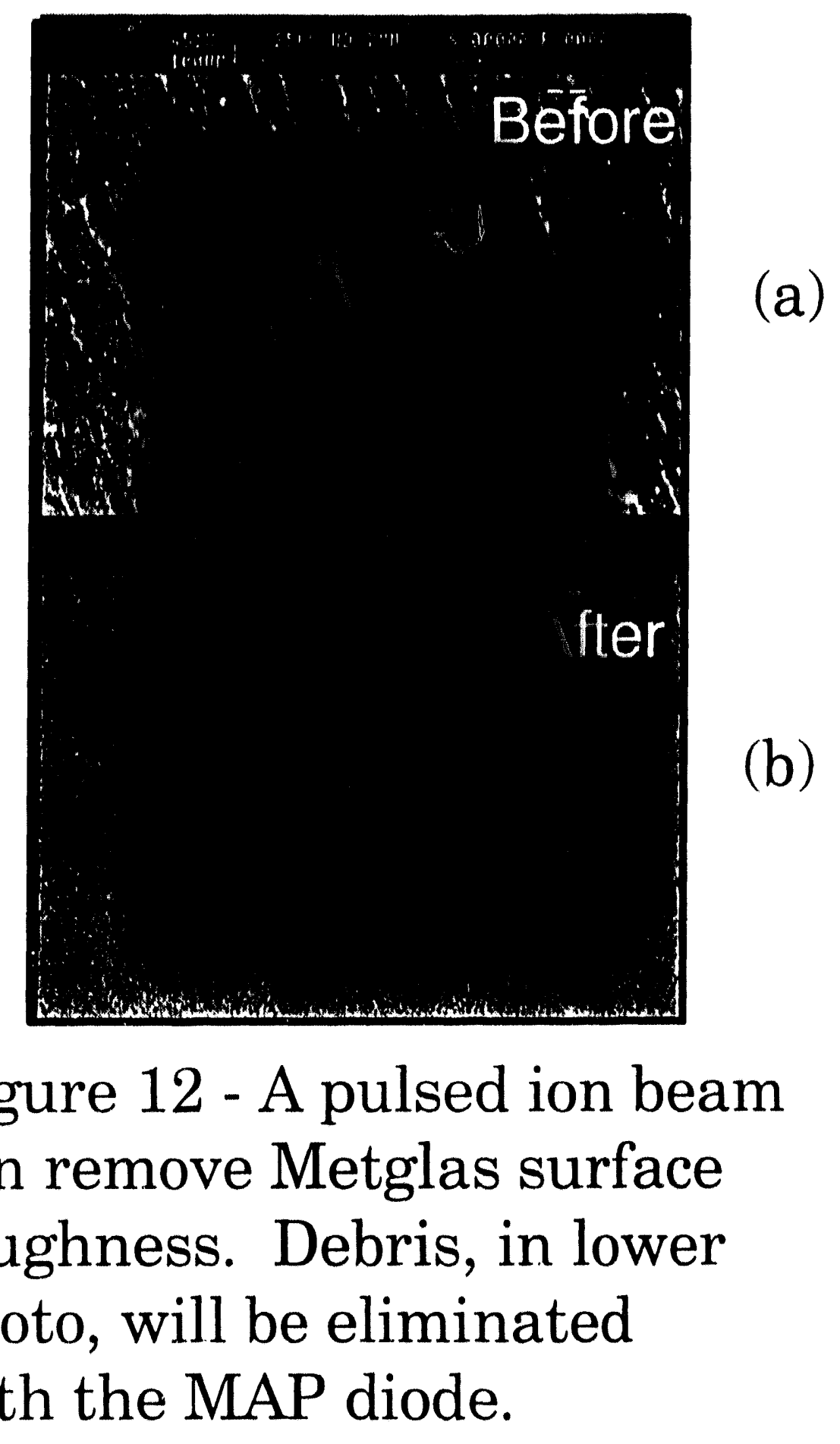



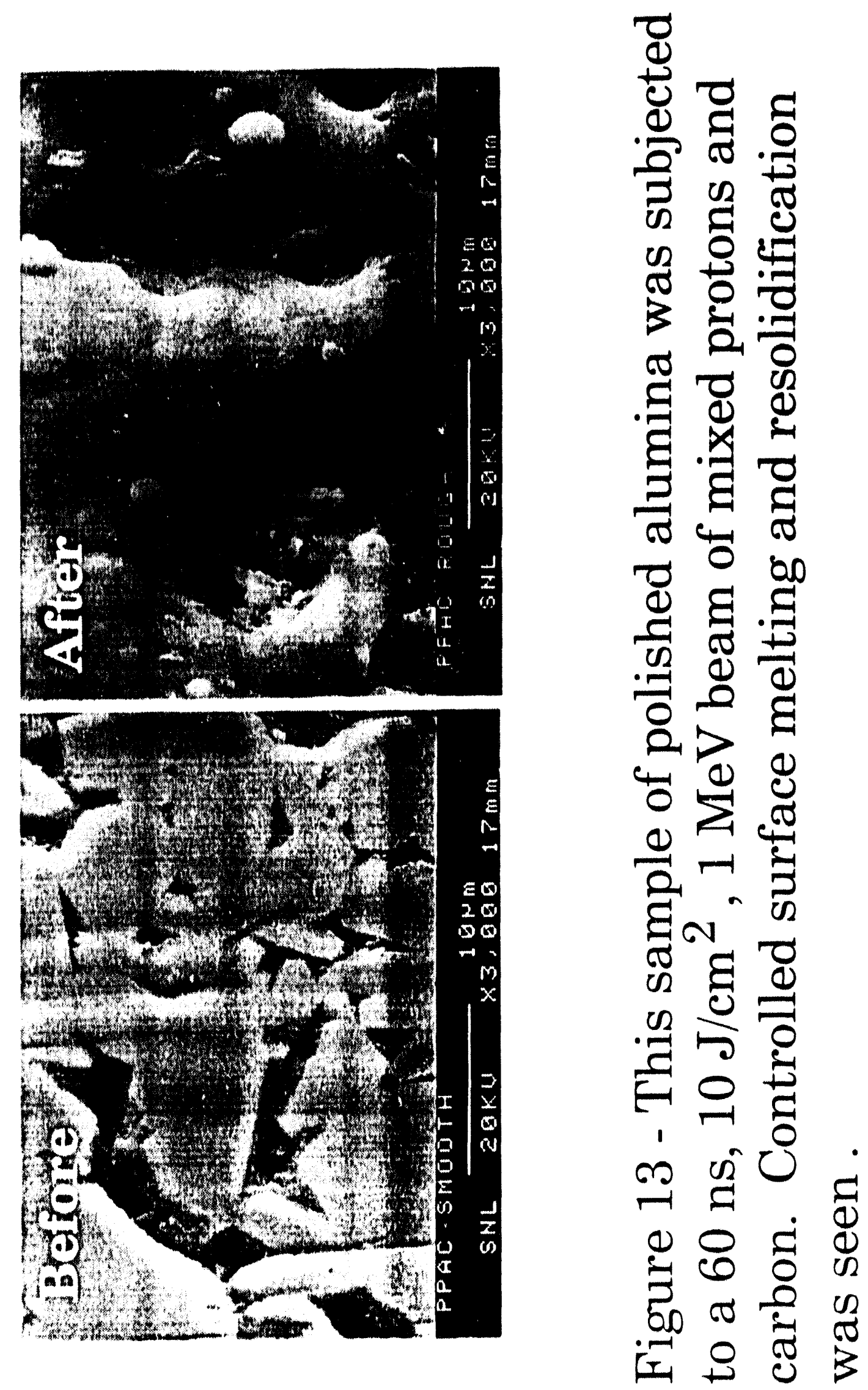


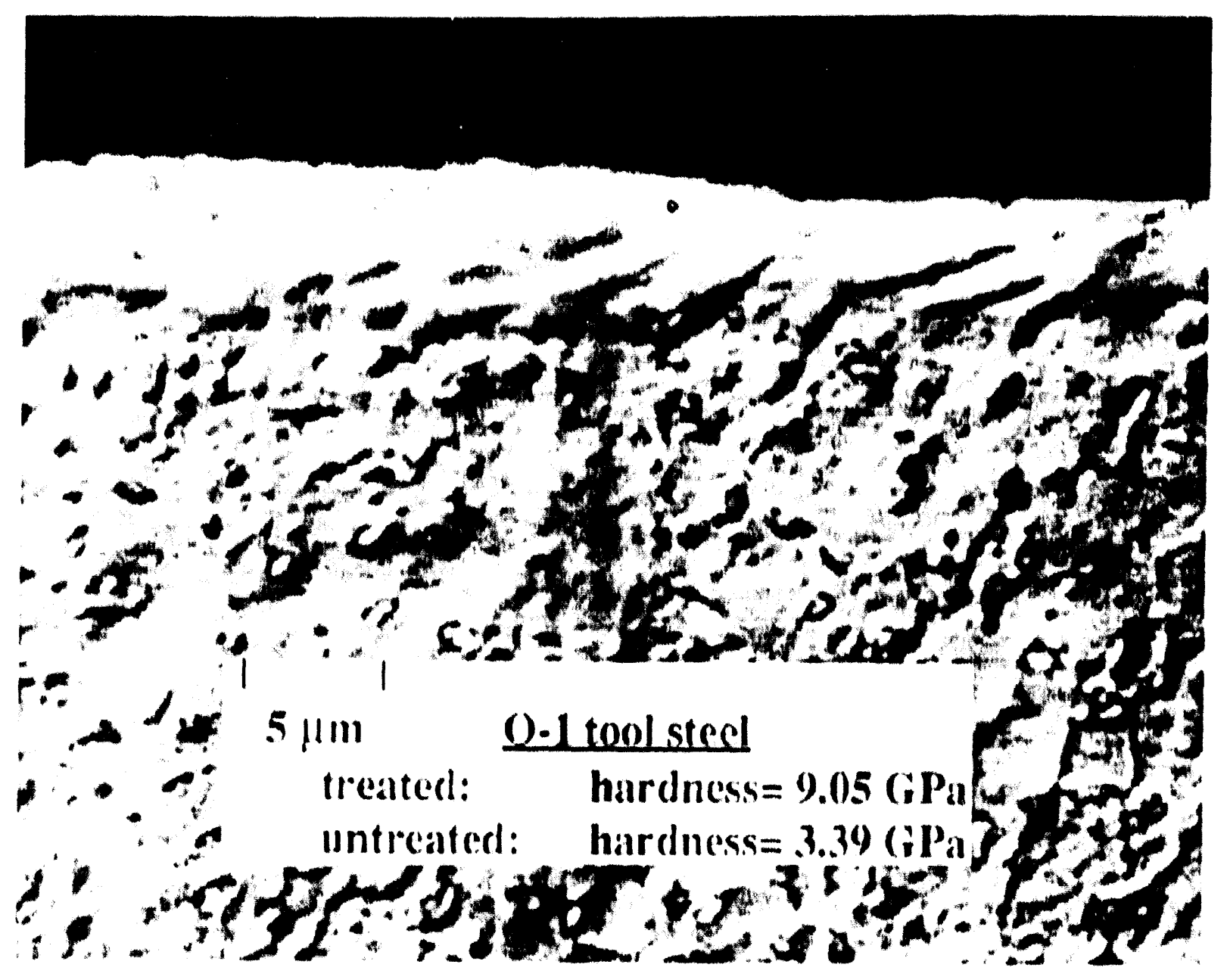

Figure 14 - Type ()-1 tool steel shows absence of equilibrium carbide structure and a $3 \mathrm{x}$ increase in surface hardness after treatment with a $10 \mathrm{~J} / \mathrm{cm}^{2}$ ion beam. 


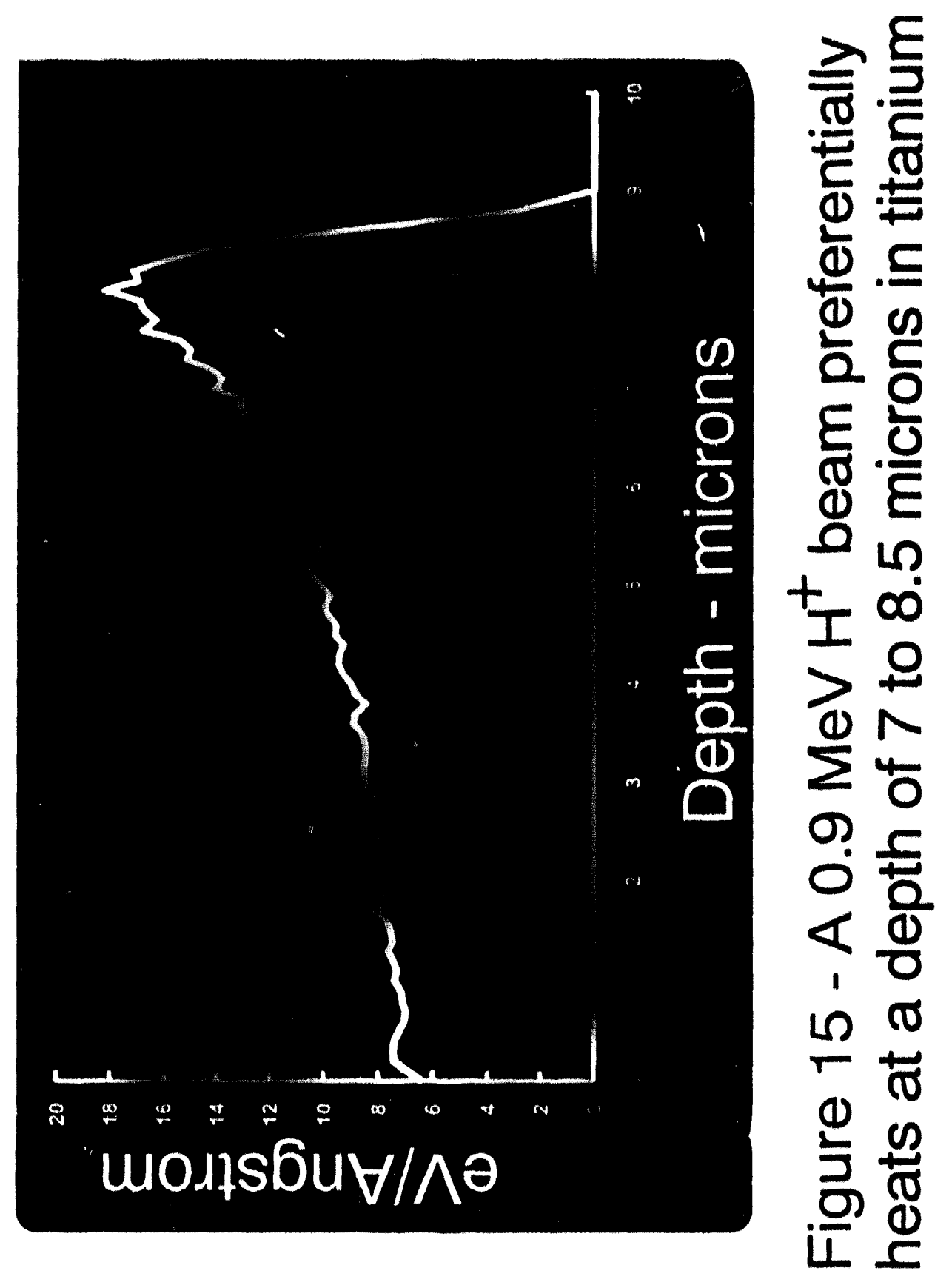




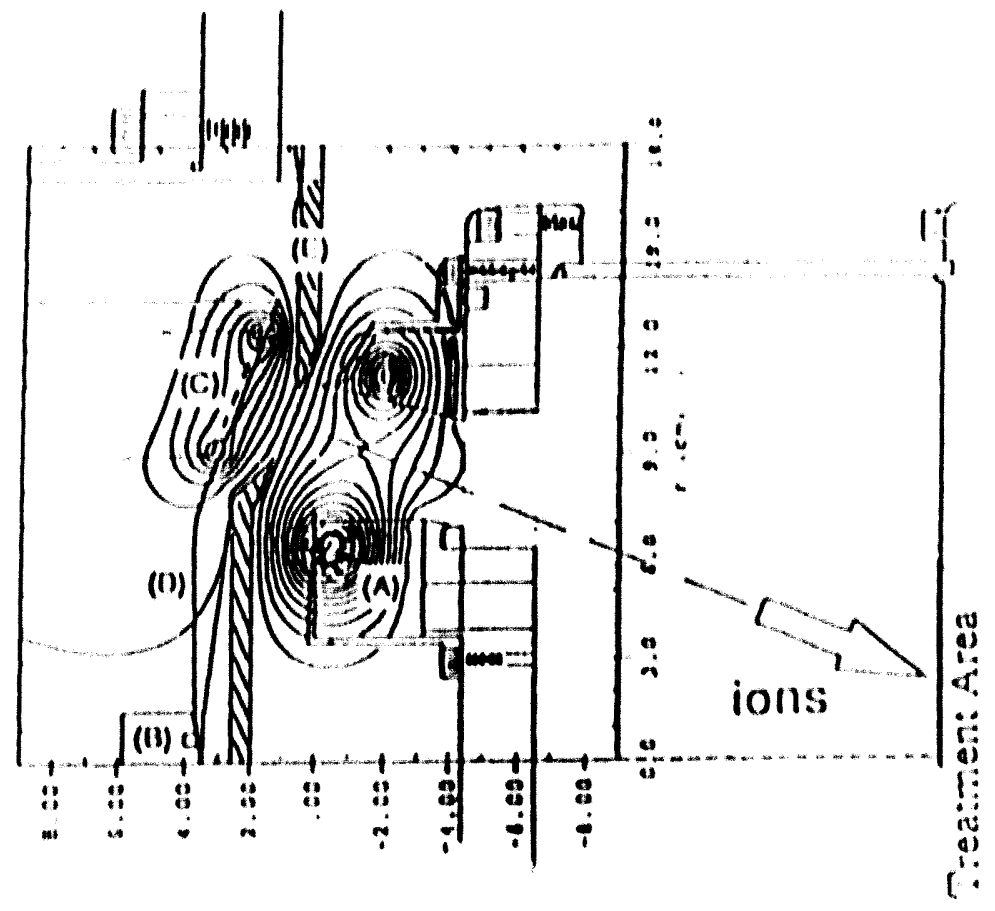

Figure 16. Thls is a schematio of the Magnet leally-confined Anode Plasma (Mal) Ion beam source. 'The cathode assembly mounted to the (negattve polarily) RHLPp output stalk is at the right. The ton beam propagates to the target plane at the rlght. 'The flgure shows the MAP diode, on the cathode side (A) the cathode magnetie insulat ing fleld colls; on the anode side (B) the puff valve; (B) the fase driving coll; (D) the gas nozrle; (b) the fleld-shaplug electrodes. The magnet fe flux surfacen superimposed are as they are at the time of the RHEll' accelorat Ins pulse which fo the present negat fve polarity operat fon la applled to the cathode structure. 

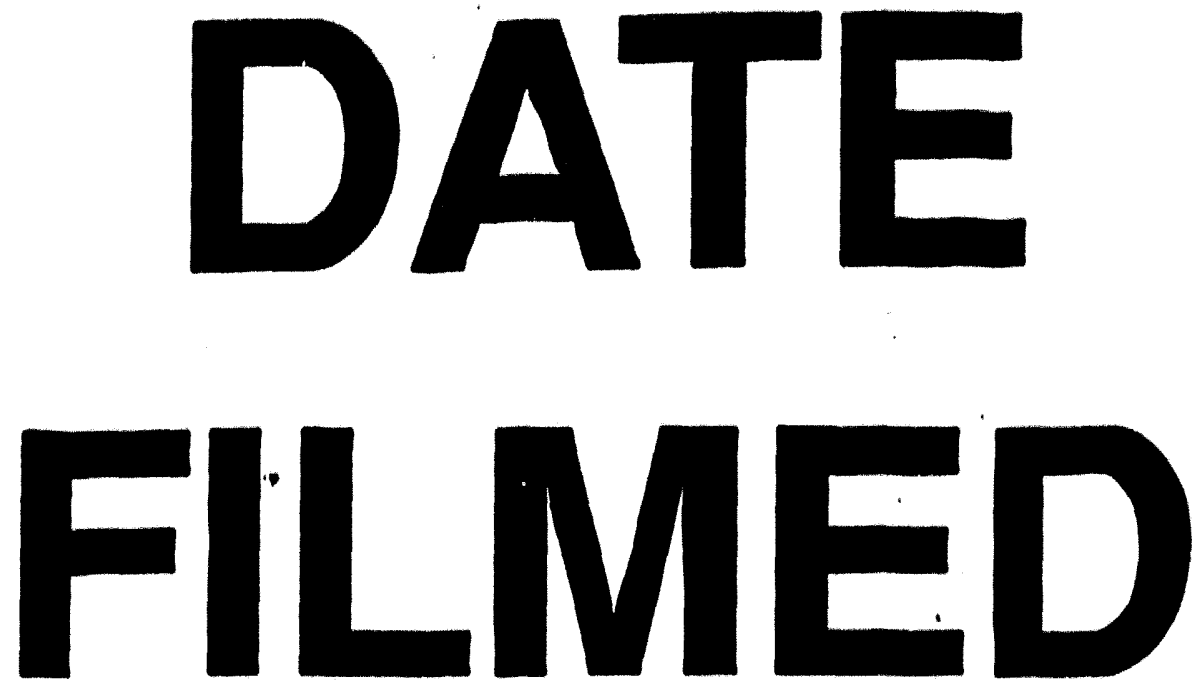

$12 / 10 / 93$
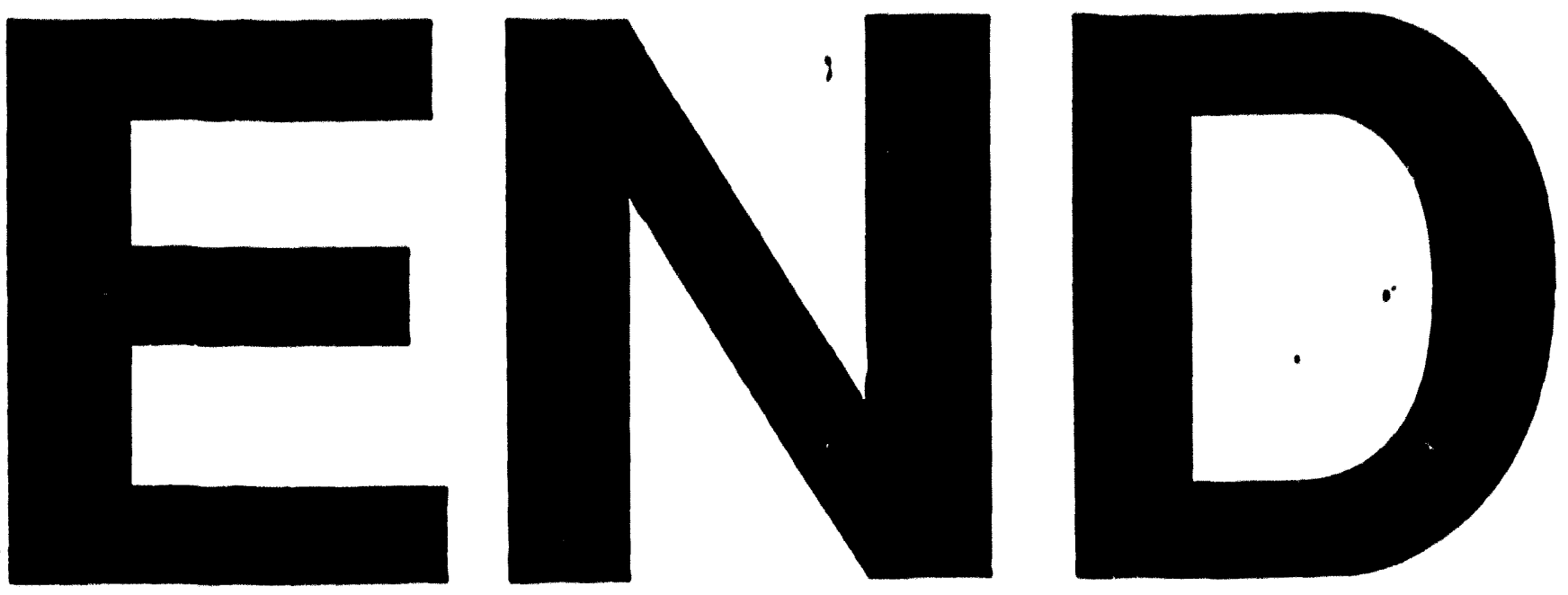
$-1$

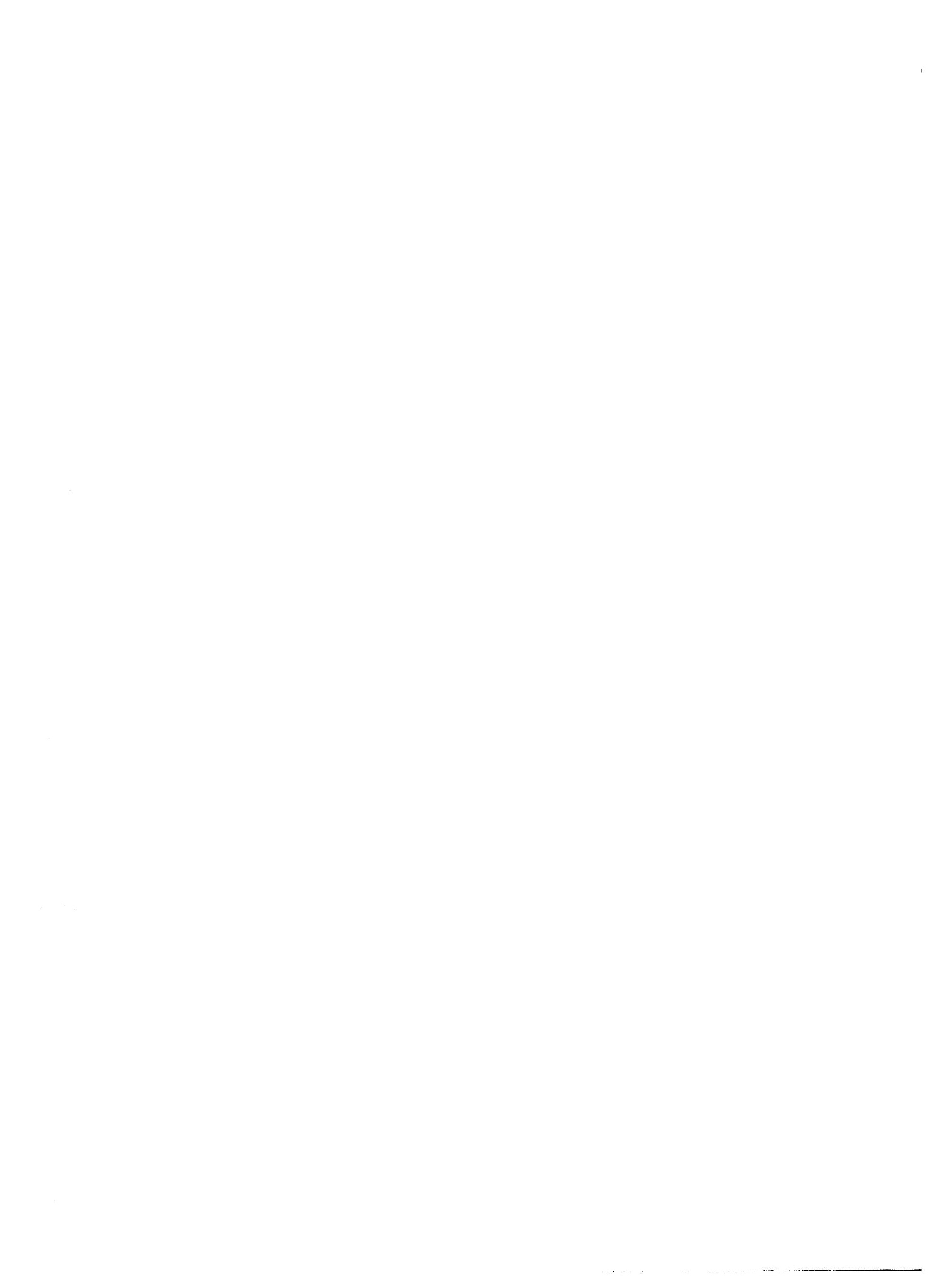

